NASA Technical Memorändum 103678 1598 AIAA-89-3519

P41

\title{
Integrated Flight/Propulsion Control System Design Based on a Decentralized, Hierarchical Approach
}

Duane Mattern and Sanjay Garg

Sverdrup Technology, Inc.

Lewis Research Center Group

Brook Park, Ohio

and

Randy Bullard

National Aeronautics and Space Administration

Lewis Research Center

Cleveland, Ohio

Presented at the

Guidance, Navigation and Control Conference

sponsored by the American Institute of Aeronautics and Astronautics

Boston, Massachusetts, August 14-16, 1989

\section{N/SN}




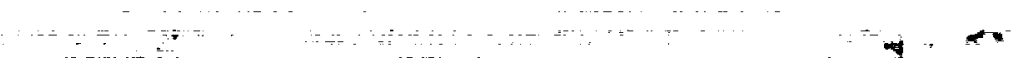

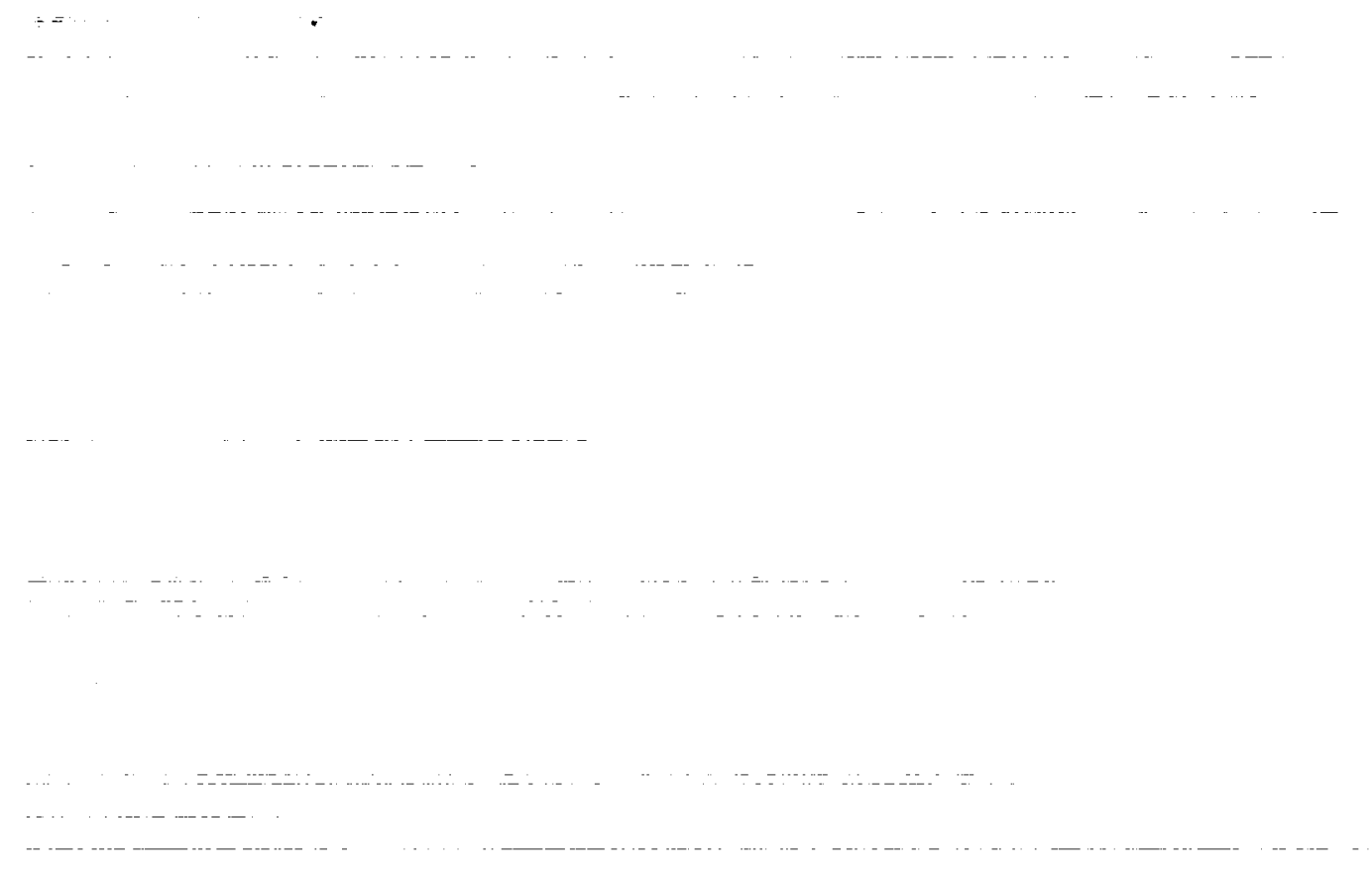

$\therefore-\cdots$

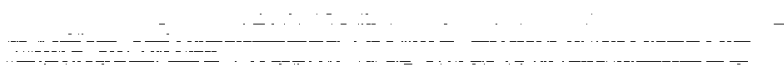

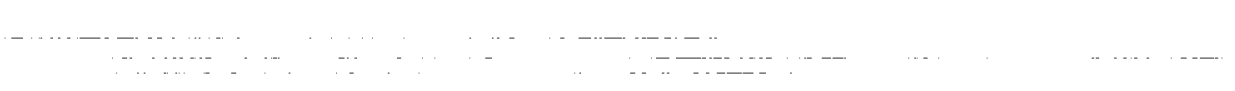




\title{
INTEGRATED FLIGHT/PROPULSION CONTROL SYSTEM DESIGN
}

\section{BASED ON A DECENTRALIZED, HIERARCHICAL APPROACH}

\author{
Duane Mattern ${ }^{1}$ and Sanjay Garg 2 \\ Sverdrup Technology, Inc. \\ Lewis Research Center Group \\ Brook Park, Ohio 44142
}

\author{
Randy Bul lard ${ }^{3}$ \\ National Aeronautics and Space Administration \\ Lew is Research Center \\ Cleveland, Ohio 44135
}

\begin{abstract}
An example integrated flight/propulsion control system design is presented for the piloted longitudinal landing task with a modern, statically unstable fighter aircraft using the decentralized/hierarchical Design Method for Integrated Control Systems (DMICS) technique. The example design begins with an open-loop analysis on the scaled, linear integrated flight and propulsion system model. This leads to a partitioning of the integrated system model into separate engine and airframe subsystems, coupled only by their outputs. The airframe subsystem inputs are then converted to "generalized" controls. The airframe control is designed using a Linear Quadratic Regulator (LQR) based, explicit model following method for the "generalized" airframe. A control selector is designed to distribute the "generalized" control inputs over the actual airframe subsystem control inputs, which include the aerodynamic control surfaces and the engine-to-airframe interface variables that result from the partitioning step. The distribution of the airframe "generalized" control requirements over the interface variables (propulsive thrusts and moments) imposes performance requirements on the engine subsystem that are used to design a command-following LQ engine control. These imposed requirements from the high-level to the low-level system define the hierarchical nature of the design method. The performance and stability of the global plant with subcontrollers is evaluated and compared to that of the individual subsystems with their own independent controller.
\end{abstract}

\footnotetext{
1Controls Engineer.

2 Controls Engineer; member, AIAA.

3 Aerospace Control Systems Engineer; present address: M.K. Ferguson Co., Cleveland, Ohio.
} 


\section{Nomenclature}

$$
\begin{aligned}
& \text { A78, A8 = thrust reverser and nozzle throat area }\left(\text { in }^{2}\right) \\
& \mathrm{EPR}=\text { engine pressure ratio } \\
& \mathrm{E}[.] \quad=\text { expected value of [.] } \\
& \mathrm{F}_{\mathrm{ex}}{ } \mathrm{F}_{\mathrm{ez}}=\text { total nozzle forces in the } \mathrm{x} \text { and } \mathrm{z} \text { direction (lbf) } \\
& \mathrm{G}(\mathrm{s})=\text { open-loop plant transfer function matrix } \\
& \mathrm{K}(\mathrm{s}) \text { = controller dynamic gain matrix } \\
& \mathrm{N} 2, \mathrm{~N} 25 \quad=\text { engine fan and core speed }(\mathrm{rpm}) \\
& \text { P6 = mixing plane pressure (psi) }
\end{aligned}
$$

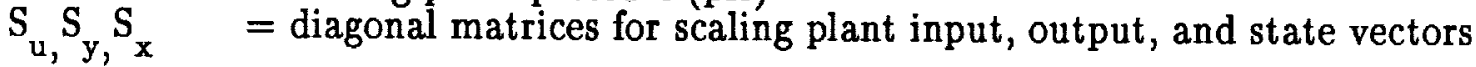

$$
\begin{aligned}
& \mathrm{T} 41 \mathrm{~B}=\text { high pressure turbine blade temperature }(\operatorname{deg} \mathrm{R}) \\
& \mathrm{T}_{\mathrm{em}} \quad=\text { total nozzle pitching moment (ft-lbs) } \\
& \mathrm{V}_{\text {sel }}=\text { pilot input, selected airspeed }(\mathrm{ft} / \mathrm{sec}) \\
& \dot{\mathrm{V}}, \mathrm{V}=\text { aircraft forward acceleration }\left(\mathrm{ft} / \mathrm{sec}^{2}\right) \text { and airspeed }(\mathrm{ft} / \mathrm{sec}) \\
& \text { WF36 = engine main fuel flow }(\mathrm{lbm} / \mathrm{hr}) \\
& \mathrm{W}_{\text {ea }}, \Gamma_{\text {ea }}=\text { airframe-to-engine interface matrices } \\
& \mathrm{W}_{\mathrm{ae}}, \Gamma_{\mathrm{ae}} \quad=\text { engine-to-airframe interface matrices } \\
& \text { a,e }=\text { airframe and engine subsystem subscripts } \\
& \text { c }=\text { commanded variable subscript } \\
& {[\cdot]_{\mathrm{h}}^{\mathrm{T}}=\text { transpose of matrix or vector }[\cdot]} \\
& \mathrm{p}, \mathrm{p}_{\mathrm{s}} \quad=\text { plant and scaled plant subscripts } \\
& \dot{\mathrm{q}}=\text { body pitch acceleration (degs } / \mathrm{sec}^{2} \text { ) } \\
& \mathrm{q}=\text { body pitch rate; state in (rads/sec); output in (degs/sec) } \\
& \text { s = the Laplace variable } \\
& \text { * = generalized variables superscript } \\
& \mathrm{u}=\text { body axis velocity }(\mathrm{ft} / \mathrm{sec}) \\
& \overline{\mathrm{u}}_{\mathrm{p}}, \overline{\mathrm{x}}_{\mathrm{p}}, \overline{\mathrm{y}}_{\mathrm{p}} \quad=\text { input, state, and output vectors for the plant } \\
& \delta_{\mathrm{FLE}}, \delta_{\mathrm{FTE}}=\text { leading edge and trailing edge flap deflection (degs) } \\
& \delta_{\text {st }} \quad=\text { pilot input, stick deflection (inches) } \\
& \delta_{\mathrm{TV}}=\text { thrust vectoring deflection (degs) } \\
& \lambda_{i}=\text { "i"th eigenvalue } \\
& \omega=\text { frequency in radians per second } \\
& \tau \quad=\text { time constant (seconds) } \\
& {[\cdot]^{\#}=\text { pseudoinverse of matrix }[\cdot] \text {. }} \\
& \text { IFPC = Integrated Flight / Propulsion Control } \\
& \text { DMICS = Design Methods for Integrated Control Systems }
\end{aligned}
$$




\section{Introduction}

Efforts to improve the maneuverability and enlarge the flight envelope of tactical aircraft via the use of propulsive moments and forces for flight control has led to an increase in coupling between the propulsion and airframe dynamics. This coupling has led to the inadequacy of the traditional approach of designing the flight and propulsion control systems separately. An integrated approach to flight/propulsion control system design is required to obtain an overall system which will yield improved performance as describe above, while reducing the pilot workload.

In the early 1980's, the U.S. Air Force initiated the Design Methods for Integrated Control Systems (DMICS) study with the objective of developing Integrated Flight/ Propulsion Control (IFPC) design methodologies for advanced tactical aircraft. The DMICS study resulted in two different approaches to the IFPC design problem:

i) a decentralized, hierarchical approach which consists of partitioning the integrated system into subsystems and then designing separate controllers for each subsystem such that the high-level performance criterion are met [1];

ii) a centralized approach which consists of designing one global compensator at each operating point for the integrated system, using a Linear Quadratic Gaussian / Loop Transfer Recovery (LQG/LTR) design technique [2].

More recently, a joint NASA Lewis and NASA Ames IFPC research program [3] has been initiated with the objective of developing the technologies that will lead to a demonstrator aircraft with Supersonic, Short Take-Off and Vertical Landing (SSTOVL) capability in the 1990's. Among the goals of this program are the development of alternatives to the DMICS methodologies, improvements in overall system performance, and simplification of the control law synthesis and implementation. Prior to considering alternative techniques, the DMICS methodologies are being reviewed to develop an understanding of the control synthesis and evaluation procedures used and to identify the strengths and weaknesses of 
these methodologies. Towards this goal, results are reported in this paper from an example application of the hierarchical, decentralized DMICS approach on a modern, statically unstable fighter aircraft for the piloted, longitudinal landing task.

In the following, the decentralized, hierarchical DMICS procedure is first summarized and its application to the example problem presented in this paper is discussed. Then, the vehicle model used in the example study is described and the procedure for partitioning the integrated system is presented, along with a description of the resulting subsystems. The high-level airframe performance specifications and control design are then presented and the control performance is evaluated. Next, the generation of the low-level (engine) subsystem specifications from the airframe requirements are discussed. The engine performance specifications are presented along with the subsystem control design. A compensator to accommodate the influence of airframe outputs on the engine subsystem is also considered. Finally, the entire closed-loop system performance and stability characteristics are examined. The paper concludes with a discussion of the strengths and weaknesses of this decentralized, hierarchical approach to the design of integrated flight/propulsion control systems.

\section{Control Law Design Methodology}

The following is a discussion of the key features of the hierarchical, decentralized DMICS procedure, based on references [1] and [4]. Figure 1 describes the flow of information required for this design method and shows that the first requirements are a vehicle and mission definition, and a nonlinear simulation of the vehicle. Assuming that these are available, the procedure begins by obtaining an integrated airframe and engine linear model by perturbing the nonlinear simulation of the system 4 . This linear model is then scaled (normalized) to perform observability, controllability, and modal analyses.

\footnotetext{
4 In reference [1] the integrated linear model was built from the individual subsystem linear models.
} 
These analyses are used to establish modal groups of inputs, outputs, and elements of the state vector for partitioning the integrated system into subsystems. Scaling is important in making relative comparisons between variables, as will be shown later in the paper. The choice of proper scaling requires physical knowledge of both the airframe and propulsion systems and a detailed description of the nominal operating point about which the integrated linear model is obtained.

After the variables are grouped into airframe and engine subsets, the system matrices are rearranged to order the variables into respective groups, resulting in the following matrix structure:

$$
\begin{aligned}
& \left(\begin{array}{c}
\dot{\bar{x}}_{\mathrm{a}} \\
\dot{\bar{x}}_{\mathrm{e}}
\end{array}\right)=\left(\begin{array}{ll}
\mathrm{A}_{11} & \mathrm{~A}_{12} \\
\mathrm{~A}_{21} & \mathrm{~A}_{22}
\end{array}\right) \cdot\left(\begin{array}{l}
\overline{\mathrm{x}}_{\mathrm{a}} \\
\overline{\mathrm{x}}_{\mathrm{e}}
\end{array}\right)+\left(\begin{array}{ll}
\mathrm{B}_{11} & \mathrm{~B}_{12} \\
\mathrm{~B}_{21} & \mathrm{~B}_{22}
\end{array}\right) \cdot\left(\begin{array}{l}
\overline{\mathrm{u}}_{\mathrm{a}} \\
\overline{\mathrm{u}}_{\mathrm{e}}
\end{array}\right) \\
& \left(\begin{array}{l}
\overline{\mathrm{y}}_{\mathrm{a}} \\
\overline{\mathrm{y}}_{\mathrm{e}}
\end{array}\right)=\left(\begin{array}{ll}
\mathrm{C}_{11} & \mathrm{C}_{12} \\
\mathrm{C}_{21} & \mathrm{C}_{22}
\end{array}\right) \cdot\left(\begin{array}{l}
\overline{\mathrm{x}}_{\mathrm{a}} \\
\overline{\mathrm{x}}_{\mathrm{e}}
\end{array}\right)+\left(\begin{array}{ll}
\mathrm{D}_{11} & \mathrm{D}_{12} \\
\mathrm{D}_{21} & \mathrm{D}_{22}
\end{array}\right) \cdot\left(\begin{array}{l}
\overline{\mathrm{u}}_{\mathrm{a}} \\
\overline{\mathrm{u}}_{\mathrm{e}}
\end{array}\right)
\end{aligned}
$$

The subscripts "a" and "e" represent variable groups for the airframe and engine, respectively. More subsystems are possible, but only engine and airframe partitions are considered in this study ${ }^{5}$. It is desired to partition the system of equations in (1\&2) such that the resulting subsystems are coupled only through their outputs (i.e., there is no direct coupling of the elements of the state vector). This desired structure is shown in Figure 2 and corresponds to the following set of equations:

$$
\begin{aligned}
& \dot{\bar{x}}_{a}=A_{a} \bar{x}_{a}+\left[B_{a} \Gamma_{a e}\right]\left\{\begin{array}{l}
\bar{u}_{a} \\
\bar{z}_{e}
\end{array}\right\} \quad \bar{y}_{a}=C_{a} \bar{x}_{a}+\left[D_{a} W_{a e}\right]\left\{\begin{array}{l}
\bar{u}_{a} \\
\bar{z}_{e}
\end{array}\right\} \\
& \dot{\bar{y}}_{e}=A_{e} \bar{x}_{e}+B_{e} \bar{u}_{e}+\Gamma_{e a} \bar{z}_{a} \quad \bar{y}_{e}=C_{e} \bar{x}_{e}+D_{e} \bar{u}_{e}+W_{e a} \bar{z}_{a}
\end{aligned}
$$

\footnotetext{
5 In reference [1], the propulsion subsystem was partitioned into inlet, gas generator and nozzle
subsystems.
} 
where

$$
\bar{z}_{a}=V_{a} \bar{y}_{a} \quad \bar{z}_{e}=V_{e} \bar{y}_{e}
$$

$\Gamma$ and $W$ are the interface matrices between subsystems and the nonsquare matrices $V_{a}$ and $V_{e}$ select the interface variables $\bar{z}_{a}$ and $\bar{z}_{e}$ from the available outputs $\bar{y}_{a}$ and $\bar{y}_{e}$. The input format in equation (3) shows that both the airframe physical controls $\left(\bar{u}_{a}\right)$ and the engine-to-airframe interface variables $\left(\bar{z}_{e}\right)$ are now considered as inputs to the airframe subsystem, while in equation (4), the airframe-to-engine interface variables $\left(\bar{z}_{\mathrm{a}}\right)$ are considered as disturbances to the propulsion subsystem. The above format is used to emphasize that the interaction from the airframe to the engine is not addressed directly in this methodology.

The objective of partitioning is to select a minimum set of interface variables $\bar{z}_{e}$ and $\bar{z}_{\mathrm{a}}$ such that the "errors" in representing the system in (1\&2) using (3\&4) are "small", in some sense. The selection of $\bar{z}_{\mathrm{a}}$ and $\overline{\mathrm{z}}_{\mathrm{e}}$ are not unique. Any combination of variables that solves the model matching problem is satisfactory. One possible solution to this model matching problem is to minimize the square error in the matrix elements as determined by comparing the system described in (1\&2) to the system description obtained by transforming the partitioned approximation of the system (3\&4) back to the integrated structure (1\&2). This approach requires that the dynamic characteristics of the system be relatively insensitive to small changes in the individual elements of the system matrices. This model matching problem requires the solution of 16 matrix equations in 12 unknown matrices, resulting in 4 matrix constraint equations, as described in the appendix.

Once constrained to the structure shown in (3\&4), the real problem in matching $(1 \& 2)$ is in the selection of a minimum number of variables $\bar{z}_{a}$ and $\bar{z}_{e}$ that represent the interface between the subsystems. The interface represents the information flow between subsystems. If the effect of this information flow is not "small", there may be a requirement for a corresponding flow of information between the subsystem controllers in 
order to obtain good performance and stability properties. Therefore, the number of interface variables should be kept small to simplify the control design and implementation. Due to the way nonlinear aircraft simulations are currently developed, a set of outputs defining the physical airframe/propulsion interface can be obtained from the software interface between the engine and airframe nonlinear simulations. Once a set of interface variables is identified and a reasonable partition is obtained, the airframe subsystem (3) is taken as the high-level plant, while the engine is considered to be a low-level subsystem (4). This hierarchy is described by Figure 1, as the airframe subsystem becomes the mission level subsystem, and the engine becomes a function level subsystem. In Figure 1, the information flow between the Mission-Level and the Function-Level refers to the requirements and capabilities of the interface variable $\bar{z}_{e}$ in terms of its closed-loop response $\frac{\bar{z}_{e}}{\bar{z}_{e}}$. In the example presented here $\bar{z}_{e}$ is comprised of propulsive thrust and moments.

Now that the separate subsystems are defined by the partitioning step, the design of the high-level airframe controller can begin. First, the high-level airframe model is reformulated as a system with "generalized" control inputs [1]. There is one generalized control input for each degree of freedom for the rigid body aircraft. For the longitudinal model used in this study there are three degrees of freedom: forward and vertical displacements and a pitch rotation. These yield three generalized control inputs, $\delta \dot{\mathbf{u}}, \delta \dot{w}$, and $\delta \dot{q}$, for the forward, vertical, and pitch acceleration equations, respectively. The generalized control inputs are scaled such that a $100 \%$ deflection yields a specific value of acceleration, based on performance specifications, maximum control authority of the high-level system, and estimates of the low-level subsystem's closed-loop performance. This defines the new input matrices $\mathrm{B}_{\mathrm{a}}^{*}$ and $\mathrm{D}_{\mathrm{a}}^{*}$, which will yield a new "generalized" plant, $\mathrm{G}_{\mathrm{a}}^{*}(\mathrm{~s})=\mathrm{D}_{\mathrm{a}}^{*}+\mathrm{C}_{\mathrm{a}}\left(\mathrm{sI}-\mathrm{A}_{\mathrm{a}}\right) \mathrm{B}_{\mathrm{a}}^{*}$. Estimates of the nominal bandwidths of the generalized 
controls are made from the known dynamic characteristics of the actual physical controls of the high-level system and the estimated closed-loop response of the low-level systems. Referring back to Figure 1, the estimated capability of the closed-loop function level subsystems are used to define the available authority and bandwidth of the generalized controls. For example, $u$ is mainly dependent on the available horizontal thrust, which is a capability that the engine provides. Thus, the bandwidth for the forward acceleration generalized actuator is defined by the estimated closed-loop horizontal thrust response.

The regulator design can now begin on the generalized plant $\mathrm{G}_{\mathrm{a}}^{*}(\mathrm{~s})$. The methodology does not dictate the technique to be used for the control design. In this paper the airframe control design is formulated as a stochastic tracking problem [5] and an explicit model-following Linear Quadratic Regulator [6] is designed for the airframe with generalized controls. The desired flight handling specifications are built into the model to be followed, called the Maneuver Command Generator (MCG) in reference [1]. The basic LQR problem can be extended to provide for frequency shaping of the performance index, but this was not used in the example study for simplicity. Frequency shaping would affect the nominal bandwidth of the generalized actuators and thus it would also affect the performance requirements imposed on the engine subsystem. Once the LQR design yields an acceptable state feedback controller, it is approximated by output feedback, since not all the states are available as measurements.

A control selector, $T(s)$, is designed to distribute the generalized control inputs over the airframe inputs for the longitudinal case show below:

$$
\left(\begin{array}{c}
\overline{\mathrm{u}}_{\mathrm{a}} \\
\overline{\mathrm{z}}_{\mathrm{e}}
\end{array}\right)=\mathrm{T}(\mathrm{s})\left(\begin{array}{c}
\delta \dot{\mathrm{u}} \\
\delta \dot{\mathrm{w}} \\
\delta \dot{\mathrm{q}}
\end{array}\right)
$$

Figure 3 shows the resulting airframe control structure. This structure will be discussed in 
detail later in the paper. Evaluation of the closed-loop system stability and performance completes the first iteration of the high-level control design. This controller design is now used to generate specifications for the engine subsystem.

The engine subsystem specifications are derived by determining the level of uncertainty in the generalized inputs that can be tolerated for stability of the high-level system. This stability robustness bound is then translated from the generalized control inputs $\left(\bar{u}_{\mathrm{a}}^{*}\right)$ to both the high-level system inputs, which consist of the airframe physical controls $\left(\bar{u}_{\mathrm{a}}\right)$ and the engine interface variables $\left(\bar{z}_{\mathrm{e}}\right)$. Reference [4] formulates this conversion as a model matching problem and presents the solution in the frequency domain. The net result is a set of nominal "actuator type" frequency response curves for the subsystem interface variables $\left(\bar{z}_{\mathrm{e}}\right)$ and a set of bounds around the nominal response that the subsystem response must fall within to guarantee the stability of the integrated system with separate controllers. For good performance, the subsystem response must match the nominal closely.

Now that the performance specifications for the engine subsystem are set, the engine compensator can be designed. Again, the methodology does not dictate a specific design approach. In this example, the subsystem design is similar to the high-level design in that a command-following LQ regulator is used. If the subcontroller design cannot meet the performance specifications, then the specifications need to be relaxed. This would require a bandwidth reduction for the generalized actuators, the redesign of the high-level regulator, the generation of a new set of subsystem specifications, and the redesign of the propulsion control. After the propulsion control design is complete, a disturbance rejection controller is considered to accommodate the influence of the airframe on the engine. This disturbance rejection controller was not required in this example problem because of the relatively weak airframe-to-engine coupling, as will be shown later. The resulting closed-loop engine subsystem control structure is shown in Figure 4. 
After evaluating the closed-loop performance of the engine subsystem controller design, the entire integrated system model response with independent subcontrollers is evaluated. The performance of the integrated system is also compared to that of the separate individual subsystems. The resulting control structure for the integrated system is shown in Figure 5.

\section{Vehicle Model}

The vehicle model consists of an integrated airframe and propulsion state-space representation of a modern fighter aircraft powered by a turbofan engine and equipped with a $2 \mathrm{D}$ thrust vectoring nozzle. The vehicle dynamics are linearized at a flight condition representative of the Short Take-Off and Landing (STOL) approach to landing task (airspeed $\mathrm{V}_{\mathrm{o}}=120$ knots, flight path angle $\gamma_{\mathrm{o}}=-3 \mathrm{deg}$.). The open-loop model is the same model as the one used in reference [7], with the addition of a few outputs. The vehicle model is defined as follows:

$$
\dot{\bar{x}}_{p}=A_{p} \bar{x}_{p}+B_{p} \bar{u}_{p} \quad \bar{y}_{p}=C_{p} \bar{x}_{p}+D_{p} \bar{u}_{p}
$$

where $\vec{x}_{p}, \bar{u}_{p}, \bar{y}_{p}$ are the perturbed state, input, and output vectors as described below:

$$
\begin{gathered}
\overline{\mathrm{x}}_{\mathrm{p}}=[\mathrm{u}, \mathrm{w}, \mathrm{q}, \theta, \mathrm{h}, \mathrm{N} 2, \mathrm{~N} 25, \mathrm{P} 6, \mathrm{~T} 41 \mathrm{~B}]^{\mathrm{T}} \\
\overline{\mathrm{u}}_{\mathrm{p}}=\left[\delta_{\mathrm{FLE}}, \delta_{\mathrm{FTE}}, \mathrm{WF} 36, \mathrm{~A} 78, \mathrm{~A} 8, \delta_{\mathrm{TV}}\right]^{\mathrm{T}} \\
\overline{\mathrm{y}}_{\mathrm{p}}=\left[\dot{\mathrm{q}}, \mathrm{q}, \theta, \dot{\gamma}, \gamma, \mathrm{V}, \mathrm{V}, \mathrm{h}, \mathrm{F}_{\mathrm{ex}}, \mathrm{F}_{\mathrm{ez}}, \mathrm{T}_{\mathrm{em}}, \mathrm{N} 2, \mathrm{EPR}\right]^{\mathrm{T}} .
\end{gathered}
$$

The vector $\bar{y}_{p}$ represents the outputs that were necessary to perform the design using this methodology. Not all the available outputs are shown and not all of the outputs shown are controlled variables. Additional outputs would be necessary in the actual implementation for rate and limit logic (rotor speeds, stall margin protection, etc.). The vehicle system matrices $A_{p}, B_{p}, C_{p}$, and $D_{p}$ are listed in the Appendix. The open-loop vehicle 
eigenvalues are

$$
\begin{gathered}
\lambda_{1}=+0.073, \quad \lambda_{2,3}=-0.094 \pm j 0.23, \quad \lambda_{4}=+1.07, \quad \lambda_{5}=-1.47 \\
\lambda_{6}=-1.40, \quad \lambda_{7}=-3.57, \quad \lambda_{8}=-6.96, \quad \lambda_{9}=-89.28
\end{gathered}
$$

Note that the airframe is statically unstable with a highly unstable pitch mode. The open-loop plant transfer function matrix $G_{p}(s)$ was full, indicating that there is coupling between the airframe and the propulsion system. However, as discussed later, the airframe-to-engine coupling is weak for this particular model.

Analysis of the control distribution matrix $\mathrm{B}_{\mathrm{p}}$ indicates that the leading and trailing edge flaps, $\delta_{\mathrm{FLE}}$ and $\delta_{\mathrm{FTE}}$, are direct-lift devices that provide indirect control of the flight path angle. The fuel flow (WF36) thrust reverser area (A78) and nozzle throat area (A8) affect the engine dynamics, and also indirectly affect the airframe dynamics through the changes in the forces and moments. The thrust vectoring angle $\delta_{\mathrm{TV}}$, while affecting the engine resultant thrust direction, is also the primary pitch control.

\section{System Partitioning}

Modal, controllability, observability, and steady-state gain analyses were performed to obtain the measures used to group the system variables. The "i"th normalized column of the modal transformation matrix $\mathrm{T}_{\mathrm{i}}$ shows how the "i"th mode, $\zeta_{\mathfrak{i}}$, contributes to the state vector $x=T_{i} \zeta_{i}$. Similarly, a column of the control effectiveness matrix in modal

coordinates, $\left(\mathrm{T}^{-1} \mathrm{~B}\right)_{\mathrm{i}}$, shows how the corresponding input affects the modes, and a row of the output matrix in modal coordinates, $(\mathrm{CT})_{\mathrm{i}}$, shows how the modes contribute to the corresponding output. The steady-state gain matrix is calculated after first stabilizing the system with an LQ control design using a heavy input cost. The unstable poles of the resulting closed-loop system were reflected about the imaginary axis and the stable poles remained fixed. The steady-state influence of the inputs on the outputs was also used to group the inputs and outputs. All of the measures described above are relative to the 
nominal operating values about which the linear model was obtained. To allow the system variables to be compared on an equal basis, each input, output, and state element was scaled so that the "expected" linear range perturbation of the scaled variable would fall in the range of \pm 1 . This allows, for example, a change in flaps of 2 degrees to be directly compared to a $500 \mathrm{lbm} / \mathrm{sec}$ change in the fuel mass flow rate. The relative magnitudes and units of the variables are taken into account in the scaling. The resulting scaled system appears below:

$$
\dot{\bar{x}}_{p_{s}}=A_{p_{s}} \bar{x}_{p_{s}}+B_{p_{s}} \bar{u}_{p_{s}} \quad \bar{y}_{p_{s}}=C_{p_{s}} \bar{x}_{p_{s}}+D_{p_{s}} \bar{u}_{p_{s}}
$$

where $\bar{x}_{p_{s}}=S_{x} \bar{x}_{p}, \quad \bar{u}_{p_{s}}=S_{u} \bar{u}_{p}$, and $\quad \bar{y}_{p_{s}}=S_{y} \bar{y}_{p}$. The scaling matrices appear in the appendix.

Tables 1 and 2 indicate the effect of scaling the modal measures used for grouping the state variables. The tables show the modal contribution to each state by displaying the normalized eigenvectors for each eigenvalue. For example, in Table 2 the fastest eigenvalue, $\lambda=-89.3$ is most evident in the mixing plane pressure (P6) and $\lambda=+1.07$ contributes most strongly to $\mathrm{q}$ and $\theta$, the unstable pitch mode. In Table 1 , the normalized "engine modes" have zero affect (to 3 decimal places) on the aircraft state elements $\mathrm{u}, \mathrm{w}, \mathrm{q}, \theta$, and $\mathrm{h}$. Comparing Table 1 to Table 2, the contribution of the "airframe modes" have little effect on the scaled engine state vector as compared to the effect on the the unscaled system. Consider the relative contribution of the complex airframe mode $(-0.094 \pm \mathrm{i} 0.23)$ to fan speed (N2). This contribution drops from 0.582 to 0.06 after scaling the system. This shows that scaling is necessary for the direct comparison of these measures of modal contribution. Examining Table 2, it is clear that the ease of grouping the elements of the state vector results from the existence of decoupled modes. This indicates that there is a relatively small amount of coupling between the airframe and engine state elements in this model, which is also apparent from the scaled system matrix, 
$A_{p_{s}}$. Controllability and observability analyses on the scaled system yield similar results.

Table 1. Normalized Columns of the Eigenvectors of the Unscaled Open-Loop System

\begin{tabular}{cccccccccc}
\hline MODES & 0.073 & 1.07 & $\begin{array}{c}-.094 \\
\pm \mathrm{i} .23\end{array}$ & -1.47 & -1.40 & -3.57 & -6.96 & -89.3 & \\
\hline 0.014 & 0.303 & 0.196 & 0.153 & & & & & & $\mathrm{u}$ \\
0000 & 1.000 & 0.045 & 1.000 & & & & & & $\mathrm{w}$ \\
0.000 & 0.006 & 0.000 & 0.006 & 0 & 0 & $\overline{0}$ & $\overline{0}$ & $\mathrm{q}$ \\
0.000 & 0.006 & 0.001 & 0.004 & & & & & $\theta$ \\
1.000 & 0.191 & 1.000 & 0.104 & & & & & & $\mathrm{~h}$ \\
& & & & & & & & & \\
0.362 & 0.108 & 0.582 & 0.430 & 1.000 & 1.000 & 1.000 & 1.000 & $\mathrm{~N} 2$ \\
0.069 & 0.017 & 0.137 & 0.191 & 0.456 & 0.267 & 0.315 & 0.088 & $\mathrm{N25}$ \\
0.003 & 0.001 & 0.003 & 0.002 & 0.005 & 0.003 & 0.002 & 0.247 & $\mathrm{P} 6$ \\
0.031 & 0.116 & 0.062 & 0.055 & 0.136 & 0.006 & 0.009 & 0.022 & $\mathrm{~T} 41 \mathrm{~B}$ \\
\hline
\end{tabular}

Table 2. Normalized Columns of the Eigenvectors of the Scaled Open-Loop System

\begin{tabular}{|c|c|c|c|c|c|c|c|c|}
\hline MODES ${ }^{0.073}$ & 1.07 & $\begin{array}{r}-.094 \\
\pm . .23\end{array}$ & -1.47 & -1.40 & -3.57 & -6.96 & -89.3 & \\
\hline $\begin{array}{l}0.072 \\
0.002 \\
0.033 \\
0.509 \\
1.000\end{array}$ & $\begin{array}{l}0.172 \\
0.454 \\
0.950 \\
1.000 \\
0.022\end{array}$ & $\begin{array}{l}0.580 \\
0.106 \\
0.222 \\
1.000 \\
0.591\end{array}$ & $\begin{array}{l}0.095 \\
0.499 \\
1.000 \\
0.762 \\
0.013\end{array}$ & $\begin{array}{l}0.007 \\
0.028 \\
0.049 \\
0.039 \\
0.001\end{array}$ & $\overline{0}$ & $\overline{0}$ & $\overline{0}$ & $\begin{array}{l}\mathbf{u} \\
\mathbf{w} \\
\mathrm{q} \\
\hat{\theta} \\
\mathrm{h}\end{array}$ \\
\hline $\begin{array}{l}0.063 \\
0.009 \\
0.008 \\
0.062\end{array}$ & $\begin{array}{l}0.002 \\
0.000 \\
0.001 \\
0.003\end{array}$ & $\begin{array}{l}0.060 \\
0.011 \\
0.006 \\
0.073\end{array}$ & $\begin{array}{l}0.010 \\
0.003 \\
0.001 \\
0.014\end{array}$ & $\begin{array}{l}0.641 \\
0.230 \\
0.055 \\
1.000\end{array}$ & $\begin{array}{l}1.000 \\
0.210 \\
0.058 \\
0.067\end{array}$ & $\begin{array}{l}1.000 \\
0.249 \\
0.043 \\
0.102\end{array}$ & $\begin{array}{l}0.212 \\
0.015 \\
1.000 \\
0.053\end{array}$ & $\begin{array}{l}\text { N2 } \\
\text { N25 } \\
\text { P6 } \\
\text { T41B }\end{array}$ \\
\hline
\end{tabular}

During the open-loop analysis of the control input effectiveness, it became apparent that the leading and trailing edge flap deflections $\delta_{\mathrm{FLE}}$ and $\delta_{\mathrm{FTE}}$ belong with the airframe subsystem, and that fuel flow (WF36), thrust reverser port area (A78), and nozzle throat area (A8), belong with the engine subsystem. The placement of the thrust vectoring angle 
$\left(\delta_{\mathrm{TV}}\right)$, was not so easily determined. $\delta_{\mathrm{TV}}$ is the primary pitch control because it determines the direction of the thrust which generates the pitching moment. The physical engine-to-airframe interface is comprised of forces and moments. Thus, it was concluded that propulsive moments and forces are a reasonable set of variables to represent the physical engine-to-airframe interaction. Since $\delta_{\mathrm{TV}}$ determines the direction of the thrust, it was grouped as an engine control input. An alternative set of interface variables could been used (mass flows for example) but from a modelling viewpoint the optimal set of coupling variables for the partitioned linear models is the same set of variables used to represent the interface between the airframe and engine in the nonlinear simulations. From a simulation stand point, there is no other set of variables that will better represent the interface information. Thus, one possible set of interface variables for partitioning the linear system is predefined by the nonlinear simulation from which the linear system was obtained.

Inlet distortion effects are one source of airframe-to-engine coupling. Although $\gamma$, $\mathrm{q}$, and 0 contribute to this coupling, the primary effects are due airspeed (V) and altitude (h) for this example problem. Mach number and pressure can be used to schedule the engine operation, and they convey the same information as $V$ and $h$. Therefore, the variations in $\mathrm{V}$ and $\mathrm{h}$ would be implicitly accounted for in the nonlinear portion of the propulsion control (the logic or schedule portion). For this particular model, the airframe-to-engine coupling is relatively small, but this will not be the case for high performance aircraft envisaged for the future.

The partitioning study resulted in the following groups of variables:

$$
\begin{aligned}
& \text { airframe state vector: } \overline{\mathrm{x}}_{\mathrm{a}}=[\mathrm{u}, \mathrm{w}, \mathrm{q}, 0, \mathrm{~h}]^{\mathrm{T}} \text { engine state vector: } \overline{\mathrm{x}}_{\mathrm{e}}=[\mathrm{N} 2, \mathrm{~N} 25, \mathrm{P} 6, \mathrm{~T} 41 \mathrm{~B}]^{\mathrm{T}} \\
& \text { airframe inputs: } \overline{\mathrm{u}}_{\mathrm{a}}=\left[\delta_{\mathrm{FLE}}, \delta_{\mathrm{FTE}}\right]^{\mathrm{T}} \quad \text { engine inputs: } \overline{\mathrm{u}}_{\mathrm{e}}=\left[\mathrm{WF}, \mathrm{A} 78, \mathrm{~A} 8, \delta_{\mathrm{TV}}\right]^{\mathrm{T}} \\
& \text { airframe interface: } \bar{z}_{\mathrm{a}}=[\mathrm{V}, \gamma, \mathrm{q}, \theta, \mathrm{h}]^{\mathrm{T}} \quad \text { engine interface: } \overline{\mathrm{z}}_{\mathrm{e}}=\left[\mathrm{F}_{\mathrm{ex}}, \mathrm{F}_{\mathrm{ez}}, \mathrm{T}_{\mathrm{em}}\right]^{\mathrm{T}}
\end{aligned}
$$

The key decision of this partitioning step was the placement of $\delta_{\mathrm{TV}}$ with the engine subsystem, as was previously described. Note that $\dot{\mathrm{q}}, \dot{\gamma}, \vec{V}, \mathrm{~N} 2$, and EPR are not necessary 
to describe the coupling between the engine and the airframe. $\bar{z}_{a}$ and $\bar{z}_{e}$ contain all the information necessary to describe the information flow between the subsystems. $\dot{\mathrm{q}}, \dot{\gamma}$, and $V$ are not needed, because the engine inlet conditions do not change as fast as these variables. N2 and EPR are not needed, because they are already represented in the thrust and moment variables.

With the variables grouped, the system can be represented by (1\&2) and then transformed to the matrix structure represented in (3\&4). This structure defines the airframe partition and the high-level regulator design can begin on the system described by equation (3).

\section{Airframe Compensator Design and Evaluation}

The design specifications for the high-level airframe control system are as follows:

(1) Track airspeed, flight path and pitch angles in a decoupled manner with zero steady-state error for step commands. The desired control bandwidths are 1 $\mathrm{rad} / \mathrm{sec}$ for the velocity loop and $5 \mathrm{rad} / \mathrm{sec}$ for both the pitch and flight path angle loops.

(2) Avoid "excessive" control deflections and rates to prevent nonlinearities due to control deflection and/or rate limiting.

(3) Maintain "adequate" stability margins in all control loops to guarantee stability in the presence of unmodelled dynamics and variation in model parameters.

To achieve these goals, an LQR based, explicit model-following control system was designed. The model to be followed, called the Maneuver Command Generator (MCG) in reference [1], was designed to meet military specifications for Level I handling qualities requirements [8]. The inputs to the MCG, $\overline{\mathrm{u}}_{\mathrm{mcg}}$, are the pilot stick deflection $(\delta)_{\mathrm{s}}$, and selected airspeed $\left(\mathrm{V}_{\text {sel }}\right)$; the MCG outputs, $\overline{\mathrm{y}}_{\mathrm{mcg}}=[\dot{\mathrm{q}}, \mathrm{q}, \theta, \dot{\gamma}, \gamma, \dot{\mathrm{V}}, \mathrm{V}]_{\mathrm{mcg}}^{\mathrm{T}}$, are the reference values for the airframe outputs to track. 
The desired responses to pilot command inputs are listed in Table 3 in transfer function form. In Table 3, the desired velocity response represents a well-damped response with minimal overshoot and a rapid settling time with a $90 \%$ rise time to a step input

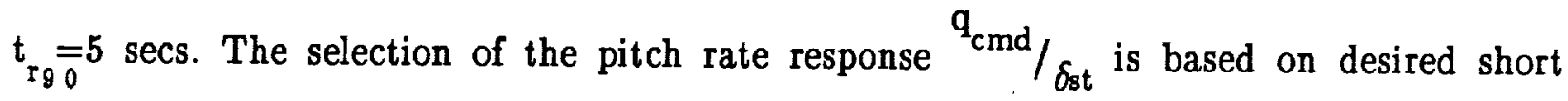
period characteristics for Level I handling qualities. Also, open-loop analysis revealed that it would not be possible to control flight path angle independent of the pitch angle. Therefore, the flight path response is such as to lag the pitch attitude response with a time constant of 0.52 seconds. This corresponds to $\tau_{\theta 2}=0.52$ in the "classical" airframe longitudinal dynamics [9]. It was desired to have $\tau_{02}>0.7$, but after open-loop analysis of the flaps, it was discovered that this would not be possible. These dynamics shown in Table 3 can also be realized in a state space representation $\left(A_{\mathrm{mcg}}, B_{m c g}, C_{m c g}, D_{m c g}\right)$.

Table 3. Desired AirFrame Response Transfer Functions

$$
\begin{gathered}
\text { Notation: }\left\{\mathrm{K}(1 / \tau)\left[\zeta ; \omega_{\mathrm{n}}\right] \equiv \mathrm{K}(\mathrm{s}+1 / \tau)\left(\mathrm{s}^{2}+2 \zeta \omega_{\mathrm{n}} \mathrm{s}+\omega_{\mathrm{n}}^{2}\right)\right\} \\
\frac{\mathrm{V}_{\mathrm{cmd}}}{\mathrm{V}_{\mathrm{se} \mathrm{l}}}=\frac{0.04(3.13)}{[0.89 ; 0.36]} ; \quad \frac{\mathrm{q}_{\mathrm{cmd}}}{\delta_{\mathrm{s} \mathrm{t}}}=\frac{35.12(0.52)}{[0.89 ; 2.24]} ; \quad \frac{\gamma}{\delta_{\mathrm{st}}}=\frac{\theta}{\delta_{\mathrm{st}}} \cdot \frac{1.92}{(0.52)}
\end{gathered}
$$

The next step in the design procedure of the high-level system is to restructure the plant inputs as generalized control inputs. For the longitudinal model there is one generalized control for each acceleration term: body axis forward acceleration ( $\delta \dot{\mathrm{u}})$, body axis vertical acceleration $(\delta \dot{\mathrm{w}})$, and pitch angular acceleration $(\delta \dot{\mathrm{q}})$. For this example, the generalized control input matrices $\mathrm{B}_{\mathrm{a}}^{*}$ and $\mathrm{D}_{\mathrm{a}}^{*}$ were determined based on maximum available accelerations in each direction using maximum deflection for the physical controls. This procedure was based on the discussion in reference [10]. Using $\bar{u}_{p} \max =[15$, $15,5000,50,100,10]$ resulted in the following generalized control input matrices: 


$$
\mathrm{B}_{\mathrm{a}}^{*}=\left(\begin{array}{ccc}
1.49 \mathrm{e}-1 & 0 & 0 \\
0 & 3.76 \mathrm{e}-2 & 0 \\
0 & 0 & 5.8 \mathrm{e}-3 \\
0 & 0 & 0 \\
0 & 0 & 0
\end{array}\right) \quad \mathrm{D}_{\mathrm{a}}=\left(\begin{array}{ccc}
0 & 0 & -3.32 \mathrm{e}-1 \\
0 & 0 & 0 \\
0 & 0 & 0 \\
-8.77 \mathrm{e}-3 & 1.05 \mathrm{e}-2 & 0 \\
0 & 0 & 0 \\
-1.46 \mathrm{e}-1 & -7.3 \mathrm{e}-3 & 0 \\
0 & 0 & 0
\end{array}\right)
$$

At this point in the design, generalized actuators would normally be included into the generalized airframe. Estimates of the bandwidths of the generalized actuators are made from the known bandwidths of the physical controls and the estimates of the closed-loop response of the engine subsystem. However, generalized actuators were not used in this example study to simplify the design. This implies an infinite bandwidth generalized actuator, which imposes an infinite bandwidth requirement on the response of the engine-to-airframe interface variables $\mathrm{F}_{\mathrm{ex}} / \mathrm{F}_{\mathrm{ex}}^{\mathrm{cmd}}, \mathrm{F}_{\mathrm{ez}} / \mathrm{F}_{\mathrm{ez}}^{\mathrm{cmd}}$, and $\mathrm{T}_{\mathrm{em}} / \mathrm{T}_{\mathrm{em}}^{\mathrm{cmd}}$. This is synonymous to designing a control for a plant without actuators and then verifying that the actuators do not affect the design. Although this overlooks an important step in the methodology, it simplified the design process while still allowing the methodology to be exercised, which is the primary purpose of this paper.

The structure of the open-loop design plant needs to be defined. To generate the error vector for the regulator design, the airframe outputs are selected to be the same as the MCG outputs $\overline{\mathbf{y}}_{\mathbf{a}}=[\dot{\mathrm{q}}, \mathrm{q}, \theta, \dot{\gamma}, \gamma, \dot{\mathrm{V}}, \mathrm{V}]^{\mathrm{T}}$. Lead information is obtained from the MCG outputs $\dot{\mathrm{q}}, \dot{\gamma}$, and $\dot{\mathrm{V}}$, but these will not be included as airframe outputs in the output feedback control design. Next, the specifications call for zero steady-state error for step commands, requiring integral action on 3 loops: pitch attitude $(\theta)$, flight path angle $(\gamma)$, and airspeed (V). Also, it was desired to design the controller for a pilot stick bandwidth of $10 \mathrm{rad} / \mathrm{sec}$ and a pilot airspeed select bandwidth of $1 \mathrm{rad} / \mathrm{sec}$. The pilot input bandwidths were modeled using first-order lags of white noise as shown below:

$$
\dot{\delta}_{\mathrm{st}}=-10 \delta_{\mathrm{st}}+10 \eta_{\delta} \quad \text { and } \quad \dot{\mathrm{V}}_{\mathrm{sel}}=-1 \mathrm{~V}_{\mathrm{sel}}+1 \nu_{\mathrm{V}}
$$

where $\eta_{\delta}$ and $\nu_{\mathrm{V}}$ are zero mean, Gaussian, white noise processes. Combining the 
generalized vehicle dynamics, the model dynamics, the integral errors and the pilot input models results in the following open-loop design structure:

$$
\begin{aligned}
& {\left[\begin{array}{l}
\dot{\bar{x}}_{\mathrm{a}}^{\mathrm{a}} \\
\dot{\overline{\mathrm{x}}}_{\mathrm{mcg}} \\
\dot{\overline{\mathrm{x}}}_{\mathrm{f}} \\
\dot{\overline{\mathrm{u}}}_{\mathrm{mcg}}^{\mathrm{e}}
\end{array}\right]=\left[\begin{array}{cccc}
\mathrm{A}_{\mathrm{a}} & 0 & 0 & 0 \\
0 & \mathrm{~A}_{\mathrm{mcg}} & 0 & \mathrm{~B}_{\mathrm{mcg}} \\
-\mathrm{C}_{\mathrm{a}}^{\mathrm{s}} & \mathrm{C}_{\mathrm{mcg}}^{\mathrm{s}} & 0 & \mathrm{D}_{\mathrm{mcg}}^{\mathrm{s}} \\
0 & 0 & 0 & \mathrm{~A}_{\mathrm{filter}}
\end{array}\right]\left[\begin{array}{l}
\overline{\mathrm{x}}_{\mathrm{a}} \\
\overline{\mathrm{x}}_{\mathrm{mcg}} \\
\overline{\mathrm{x}}_{\int \mathrm{e}} \\
\overline{\mathrm{u}}_{\mathrm{mcg}}
\end{array}\right]+\left[\begin{array}{c}
\mathrm{B}_{\mathrm{a}}^{*} \\
0 \\
-\mathrm{D}_{\mathrm{a}}^{* \mathrm{~s}} \\
0
\end{array}\right] \overline{\mathrm{u}}_{\mathrm{a}}^{*}+\left[\begin{array}{c}
0 \\
0 \\
0 \\
\mathrm{~B}_{\text {filter }}
\end{array}\right]\left[\begin{array}{l}
\eta_{\delta} \\
\nu_{\mathrm{v}}
\end{array}\right]} \\
& {\left[\begin{array}{l}
\bar{y}_{\text {mcg }} \\
\bar{y}_{\text {err }} \\
\bar{y}_{\text {je }}
\end{array}\right]=\left[\begin{array}{cccc}
0 & C_{m c g} & 0 & D_{m c g} \\
-C_{a} & C_{m c g} & 0 & D_{m c g} \\
0 & 0 & I & 0
\end{array}\right]\left[\begin{array}{l}
\bar{x}_{a} \\
\bar{x}_{m c g} \\
\bar{x}_{f e} \\
\bar{u}_{m c g}
\end{array}\right]+\left[\begin{array}{c}
0 \\
-D_{a}^{*} \\
0
\end{array}\right] \bar{u}_{a}^{*}}
\end{aligned}
$$

The superscript "s" indicates a submatrix, since the integral errors on $[\theta, \gamma, \mathrm{V}]$ are a subset of the error vector $\overline{\mathrm{e}}=\overline{\mathrm{y}}_{\text {mcg }}-\overline{\mathrm{y}}_{\mathrm{a}}=\left[\mathrm{e}_{\dot{q}}, \mathrm{e}_{\mathrm{q}}, \mathrm{e}_{\theta}, \mathrm{e}_{\dot{\gamma}}, \mathrm{e}_{\gamma}, \mathrm{e}_{\dot{\mathrm{v}}}, \mathrm{e}_{\mathrm{v}}\right]^{\mathrm{T}}$. The zeros are zero matrices of appropriate size. The subscript " $a$ " describes the generalized airframe. $A_{\text {filter }}$ and $B_{\text {filter }}$ describe the state space model of the pilot inputs $\bar{u}_{\text {mcg }}$ described in equation (10).

Minimizing the following performance index results in an optimal state feedback compensator $\mathrm{K}_{\mathbf{x}}$ :

$$
J=E\left\{\lim _{T \rightarrow \infty} \frac{1}{T} \int_{0}^{T}\left(\bar{e}^{T} Q \bar{e}+\bar{u}^{T} R \bar{u}\right) d t\right\}
$$

for a system of the form

$$
\dot{\bar{x}}_{0}=\mathrm{A}_{0} \overline{\mathrm{x}}_{0}+\mathrm{B}_{0} \overline{\mathrm{u}}_{0}+\Gamma \xi \quad \overline{\mathrm{y}}_{\mathrm{o}}=\mathrm{C}_{0} \overline{\mathrm{x}}_{\mathrm{o}}+\mathrm{D}_{0} \overline{\mathrm{u}}_{0}
$$

where $\xi$ is a zero-mean, Gaussian white noise process with identity intensity, $\Gamma$ is the noise distribution matrix, $\bar{y}_{0}$ are the output measurements, and $Q$ (positive semidefinite) and $R$ (positive definite) are symmetric weighting matrices. The subscript "o" indicates the open-loop design plant described in (11\&12). The optimal state feedback solution yields a 
set of feedback gains corresponding to the design state vector as shown below:

$$
\overline{\mathrm{u}}_{\mathrm{a}}^{*}=\mathrm{K}_{\mathrm{x}} \cdot \overline{\mathrm{x}}_{\mathrm{o}}=\left[\begin{array}{lll}
3 \times 5 & 3 \times 7 & \mathrm{~K}_{\mathrm{a}^{\prime}}, \mathrm{K}_{\mathrm{mcg}}, \mathrm{K}_{\int \mathrm{e}^{\prime}} \mathrm{K}_{\mathrm{u}_{\mathrm{p}}}
\end{array}\right] \cdot\left[\begin{array}{l}
\overline{\mathrm{x}}_{\mathrm{a}} \\
\overline{\mathrm{x}}_{\mathrm{mcg}} \\
\overline{\mathrm{x}}_{\mathrm{j}} \\
\overline{\mathrm{u}}_{\mathrm{p}}
\end{array}\right]
$$

The gains on the pilot inputs $K_{u_{p}}$ are feedforward, while the remaining state feedback gains $\mathrm{K}_{\mathrm{a}}, \mathrm{K}_{\mathrm{mcg}}$, and $\mathrm{K}_{\int_{\mathrm{e}}}$ are transformed to output feedback gains resulting in a set of gains on the system outputs as shown below:

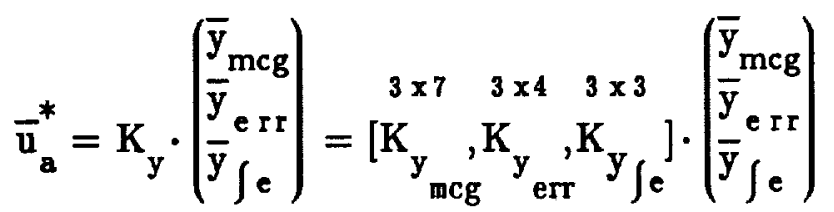

The gain matrix $\mathrm{K}_{\mathrm{y}}$ is dimension $3 \times 4$ because it does not include the outputs $\dot{\mathrm{q}}, \dot{\gamma}$, and $\vec{V}$ as stated previously. The state feedback conversion to output feedback was accomplished using matrix algebra and the resulting response matched the state feedback response. The resulting control structure is shown in Figure 3, which shows that this control law design results in a multivariable, proportional plus integral (PI) controller with additional feedforward gain matrices $\mathrm{K}_{\mathrm{u}}$ and $\mathrm{K}_{\mathrm{y}}$. The integral gains $\mathrm{K}_{\mathrm{y}}$. The only on the $\gamma, 0$, and $\mathrm{V}$ loops, while $\mathrm{K}_{\mathrm{y}}$ is the matrix of proportional gains. In evaluating the performance of the control design, the generalized control inputs were checked for rate and magnitude limits for step response inputs to $\delta_{\mathrm{st}}=1$ inch and $\mathrm{V}_{\mathrm{sel}}=20 \mathrm{ft} / \mathrm{s}$. The closed-loop bandwidths were acceptable for all loops.

To this point, the controller has been designed for the generalized plant with generalized control inputs. After acceptable output feedback control performance has been obtained on the generalized plant, the next step in the methodology is to design a control selector which transforms the required generalized controls to the available physical 
controls, as in equation (6). The control selector can be complex (including dynamics, reconfiguration and fault accommodation logic, etc.), but to simplify the design, a constant gain control selector was used in this study. The idea is to transform the generalized control inputs to the physical airframe inputs and the subsystem interface variables as shown below:

$$
\mathrm{B}_{\mathrm{a}}^{*} \overline{\mathrm{u}}_{\mathrm{a}}^{*}=\mathrm{B}_{\mathrm{a}}\left[\begin{array}{l}
\overline{\mathrm{u}}_{\mathrm{a}} \\
\overline{\mathrm{z}}_{\mathrm{e}}
\end{array}\right]
$$

A simple solution is to minimize the square error using a pseudoinverse, which results in the following:

$$
\left[\begin{array}{c}
\overline{\mathrm{u}}_{\mathrm{a}} \\
\overline{\mathrm{z}}_{\mathrm{e}}
\end{array}\right]=\mathrm{B}_{\mathrm{a}}^{\#} \cdot \mathrm{B}_{\mathrm{a}}^{*} \overline{\mathrm{u}}_{\mathrm{a}}^{*}=\mathrm{T} \overline{\mathrm{u}}_{\mathrm{a}}^{*}
$$

Scaling the variables before using the pseudoinverse yields an even distribution of the relative residual errors and a control selector design that distributes the generalized control requirements uniformly over the available control effectors. During the design, it was discovered that this particular aircraft model had been linearized at an operating point where the propulsive lift port was closed. Thus, propulsive lift is limited to the thrust vectoring nozzle and the total propulsive lift will be less than what should be available from this aircraft. For this reason, the control selector was then modified such that it does not request any lift from the propulsion system $\left(\mathrm{F}_{\mathrm{ez}}^{\mathrm{cmd}}=0\right)$ by setting the corresponding elements of $\mathrm{T}$ to zero. This places an additional lift burden on the airframe, which results in large flap deflections for certain maneuvers.

The closed-loop stability and performance of the high-level controller with the control selector were evaluated on the nongeneralized plant and found to closely match that of the generalized plant. The resulting frequency responses of $\mathrm{V} / \mathrm{V}_{\text {sel }}$ and $\mathrm{q} / \delta_{\mathrm{st}}$ are compared to the desired MCG frequency responses in Figure 6 and 7. Figure 6 shows that the frequency response of the aircraft airspeed to the pilot velocity select command closely 
follows the desired MCG response out to the bandwidth of interest. Figure 7 shows that the pitch rate response closely matches the desired MCG frequency response, until about 2 $\mathrm{rad} / \mathrm{sec}$ where the magnitude response runs about 2-3 db larger than the desired MCG response. This does not degrade the time response, as will be shown later.

\section{Subsystem Specification Generation}

The generalized actuators describe a set of nominal bandwidth requirements for the generalized controls. This bandwidth requirement can be translated from the generalized controls to the physical airframe controls $\left(\bar{u}_{a}\right)$ and the interface variables $\left(\bar{z}_{e}\right)$ through the control selector $(T)$. The level of uncertainty that the high-level system can tolerate for stability now needs to be calculated. Lehtomaki et al. [11] have shown that for multi-input multi-output systems, the minimum singular value of the return difference matrix $\sigma[\mathrm{I}+\mathrm{KG}]$ is a reliable measure of closed-loop system stability robustness to unstructured uncertainties occurring at the plant input. This uncertainty on the generalized inputs can be translated to the physical airframe and the airframe-to- engine interface variables as described in [4]. The result is a set of nominal bandwidth requirements for $\mathrm{F}_{\mathrm{ex}} / \mathrm{F}_{\mathrm{ex}}^{\mathrm{cmd}}, \mathrm{F}_{\mathrm{ez}} / \mathrm{F}_{\mathrm{ez}}^{\mathrm{cmd}}$, and $\mathrm{T}_{\mathrm{em}} / \mathrm{T}_{\mathrm{em}}^{\mathrm{cmd}}$, and a tolerance around each nominal response denoting the response requirement for stability of the high-level system.

This example study was simplified by not using generalized actuators, which implies an infinite bandwidth, which was discussed previously. Rather than calculating a stability bound on the subsystem response as in [4], the change in robustness due to the addition of the lower level system into the integrated system will be shown.

\section{Propulsion Compensator Design and Evaluation}

The gross thrust level of a turbofan engine can be controlled by using feedback control on the fan or compressor rotor speed and the engine pressure ratio [12]. Based on engine thrust performance requirements and open-loop engine control effectiveness, the desired 
control bandwidths were chosen as $5 \mathrm{rad} / \mathrm{sec}$ for the $\mathrm{N} 2$ loop and $10 \mathrm{rads} / \mathrm{sec}$ for the EPR loop. The control structure used in this study assumes the propulsion system receives setpoint information for N2 and EPR from an engine schedule as shown in Figure 4. The interface variables $\mathrm{F}_{\mathrm{ex}}$ and $\mathrm{T}_{\mathrm{em}}\left(\mathrm{F}_{\mathrm{ez}}^{\mathrm{cmd}}=0\right.$ as discussed earlier) are included in the closed-loop design, but integral control of the interface variables is the responsibility of the high-level system. For example, if there is a high-level velocity error, the error integral will accumulate and increase the request for propulsive thrust from the engine subsystem. The high-level system drives the request for thrust and there is no need for integral control of the net moments or forces in the engine subsystem. A feedforward gain matrix was used to compensate for steady-state errors at the nominal operating point. The specifications for $\mathrm{F}_{\mathrm{ex}}$ and $\mathrm{T}_{\mathrm{em}}$ were taken from the thrust vectoring actuator bandwidth.

Table 4. Desired Engine Response Transfer Functions

$$
\begin{gathered}
\text { Notation: }\left\{\mathrm{K}(1 / \tau)\left[\zeta ; \omega_{\mathrm{n}}\right] \equiv \mathrm{K}(\mathrm{s}+1 / \tau)\left(\mathrm{s}^{2}+2 \zeta \omega_{\mathrm{n}} \mathrm{s}+\omega_{\mathrm{n}}^{2}\right)\right\} \\
\frac{\mathrm{N} 2}{\mathrm{~N} 2}=\frac{5.0}{(5.0)} ; \quad \frac{\mathrm{EPR}}{\mathrm{EPR}}=\frac{10.0}{(10.0)} ; \quad \frac{\mathrm{F}_{\mathrm{ex}}}{\mathrm{F}_{\mathrm{ex}}^{\mathrm{cmd}}}=\frac{15.0}{(15.0)} ; \quad \frac{\mathrm{T}_{\mathrm{em}}}{\mathrm{T}_{\mathrm{em}}^{\mathrm{cmd}}}=\frac{15.0}{(15.0)}
\end{gathered}
$$

The $\mathrm{F}_{\mathrm{ex}}$ and $\mathrm{T}_{\mathrm{em}}$ responses were only limited by this actuator bandwidth due to the direct feed-through terms in the engine subsystem " $D$ " matrix.

The engine control design was formulated as a command following problem. This is similar to the explicit model-following approach used in the high-level design, except there is no model to be followed, so the commands are directly tracked. Since zero steady-state error for step inputs was desired for the N2 and EPR loops, two integral errors were appended to the system equations. Actuator dynamics for fuel flow (WF36), thrust reverser area (A78), nozzle throat area (A8), and thrust vectoring $\left(\delta_{\mathrm{TV}}\right)$, were incorporated into the design plant model. The engine actuator dynamics were approximated with four first-order filters with time constants of $0.1,0.033,0.033$, and 0.033 seconds [12], which are 
realized by the state space matrices $\mathrm{A}_{\text {act }}$ and $\mathrm{B}_{\text {act }}$. Models of the commanded input signals, $\overline{\mathrm{u}}_{\mathrm{cmd}}=\left[\mathrm{N} 2^{\mathrm{cmd}}, \mathrm{EPR}^{\mathrm{cmd}}, \mathrm{F}_{\mathrm{ex}}^{\mathrm{cmd}}, \mathrm{T}_{\mathrm{em}}^{\mathrm{cmd}}\right]^{\mathrm{T}}$ were approximated by four first-order filters with time constants of $0.1,0.067,0.067$, and 0.067 seconds, respectively, which are realized in state space description by $A_{\text {fil }}$ and $B_{\text {fil }}$. The resulting open-loop design structure is as follows:

$$
\begin{aligned}
& {\left[\begin{array}{l}
\dot{\bar{x}}_{\mathrm{e}} \\
\dot{\overline{\mathrm{x}}}_{\mathrm{fe}} \\
\dot{\bar{u}}_{\mathrm{e}} \\
\dot{\overline{\mathrm{u}}}_{\mathrm{cmd}}
\end{array}\right]=\left[\begin{array}{cccc}
\mathrm{A}_{\mathrm{e}} & 0 & \mathrm{~B}_{\mathrm{e}} & 0 \\
-\mathrm{C}_{\mathrm{e}}^{\mathrm{B}} & 0 & -\mathrm{D}_{\mathrm{e}}^{\mathrm{s}} & \mathrm{I} \\
0 & 0 & \mathrm{~A}_{\mathrm{act}} & 0 \\
0 & 0 & 0 & \mathrm{~A}_{\mathrm{fil}}
\end{array}\right]\left[\begin{array}{l}
\overline{\mathrm{x}}_{\mathrm{e}} \\
\overline{\mathrm{x}}_{\mathrm{f}} \\
\overline{\mathrm{u}}_{\mathrm{e}} \\
\overline{\mathrm{u}}_{\mathrm{cmd}}
\end{array}\right]+\left[\begin{array}{c}
0 \\
0 \\
\mathrm{~B}_{\mathrm{act}} \\
0
\end{array}\right] \overline{\mathrm{u}}_{\mathrm{e}}+\left[\begin{array}{c}
0 \\
0 \\
0 \\
\mathrm{~B}_{\mathrm{fil}}
\end{array}\right] \zeta_{\text {noise }}} \\
& {\left[\begin{array}{l}
\bar{y}_{e r r} \\
\bar{y}_{\int e}
\end{array}\right]=\left[\begin{array}{cccc}
-C_{e} & 0 & -D_{e} & I \\
0 & I & 0 & 0
\end{array}\right]\left[\begin{array}{l}
\bar{x}_{e} \\
\bar{x}_{\int e} \\
\bar{u}_{e} \\
\bar{u}_{c m d}
\end{array}\right]+\left[\begin{array}{l}
0 \\
0 \\
0
\end{array}\right] \bar{u}_{e}}
\end{aligned}
$$

where $\bar{u}_{e}=\left[W F 36, A 78, A 8, \delta_{T V}\right]^{T}$ and $\bar{y}_{e r r}=$ errors on $\left[N 2, E P R, F_{e x}, T{ }_{e m}\right]^{T}$. Again, the superscript "s" signifies a submatrix since only the integral errors of N2 and EPR are used, and these are a subset of the output errors $=y_{\mathrm{cmd}}-\mathrm{y}_{\text {eng }}$. Minimization of a quadratic performance measure for the system given by $(19 \& 20)$ by using the well known LQR solution yields a full state feedback controller. This controller was used to complete this study because all of the engine states can be measured except for T41B, which may be estimated using $\mathrm{P} 6$ and $\mathrm{T} 7$, the measurable nozzle inlet temperature. The full state feedback engine control was used to complete this study. The resulting control structure is shown in Figure 4 and equation (21) as

$$
u_{e}=K_{x_{e}} x_{e}+K_{\int_{e}} x_{e}+K_{e} x_{e}+K_{u_{c m d}} u_{c m d}
$$


The frequency response plots for $\mathrm{N} 2 / \mathrm{N} 2^{\mathrm{cmd}}, \mathrm{EPR} / \mathrm{EPR}^{\mathrm{cmd}}, \mathrm{F}_{\mathrm{ex}} / \mathrm{F}_{\mathrm{ex}}^{\mathrm{cmd}}$, and $\mathrm{T}_{\mathrm{em}} / \mathrm{T}_{\mathrm{em}}^{\mathrm{cmd}}$ are shown in Figures 8 and 9 . Note that all responses meet the specifications stated in Table 4. The EPR bandwidth ${ }^{6}$ is actually larger than desired and an additional filter may be required to increase the rolloff at higher frequencies. This wide bandwidth for the EPR response was required in order to obtain the desired response for the fan speed due to the coupling between EPR and N2. The propulsive thrusts and moment responses have large contributions from the direct feed-through terms (" $\mathrm{D}$ " matrix) that are related directly to the thrust vectoring angle. Therefore, the responses of the propulsive forces and moment are only limited by the thrust vectoring actuators. This is why the responses for $\mathrm{F}_{\mathrm{ex}}$ and $\mathrm{T}_{\mathrm{em}}$ roll off after a frequency of $30 \mathrm{rad} / \mathrm{sec}$.

With the engine regulator designed, attention can be focused on the accommodation of the airframe-to-engine coupling. By cross feeding the airframe-to-engine coupling variables $(\mathrm{V}, \gamma, \mathrm{q}, 0$, and $\mathrm{h})$, a "measurable" disturbance accommodation controller can be constructed as shown in Figure 4. After investigating the effects of the airframe-to-engine coupling, it was determined that this additional control was not necessary for this longitudinal model because this coupling was weak. To show this weak coupling the magnitude of the frequency responses for forward thrust $\left(F_{e x}\right)$ to the engine inputs (WF36,A8,A78,V, $\gamma, \theta, \mathrm{h}$ ) are shown in Figure 10. Note that the largest effects due to $h$ and $\mathrm{V}$ are small, relative to the effect of $\mathrm{A78}$ and $\mathrm{A8}$. The altitude (h) has the largest effect, but it would normally be part of the nonlinear engine control logic (i.e., engine operating point as a function of altitude). Also, this operating point is $h=100$ feet, so the expected linear range for $h$ is less than 100 feet. Thus, the disturbance accommodation filter was not required for this example.

6 Here, we use the accepted measure for bandwidth as the $-3 \mathrm{~dB}$ amplitude point or -45 degrees phase,
whichever occurs at the lower frequency. 


\section{Global Compensated System Evaluation}

The separate subsystem controllers were used to control the integrated, global plant as shown in Figure 5. The closed-loop eigenvalues of the integrated system compare well with the eigenvalues of the individual subsystems. A comparison of the frequency responses of the pitch rate and airspeed to pilot stick and pilot velocity select are shown in Figures 6 and 7. Figure 11 shows the time response of the airspeed, pitch rate and pitch angle for a doublet pilot stick input. Note that the integrated system closely matches the desired response of the MCG. Figure 12 compares the time response of the integrated system to that of the airframe alone and to the MCG, for a step input to the pilot velocity select command. Note that the response to $\mathrm{V}_{\text {sel }}$ is reasonably decoupled from the flight path angle. Also, the state of the engine is not largely affected by this step command. The net result is a stable system that tracks the Maneuver Command Generator responses to the pilot inputs. And finally, Figure 13 compares the singular values of the return difference matrix $I+K(s) G(s)$, plotted versus frequency for the airframe and the integrated system. In this figure there are 6 plots, but only 3 appear because the others match so closely. This figure shows no increase in uncertainty, due to the addition of the propulsion subsystem dynamics (i.e. the additional thrust dynamics does not drastically affect the airframe performance).

\section{Conclusion}

The objective of this study was to gain an understanding of the Decentralized, Hierarchical Integrated Flight/Propulsion Control design methodology that was developed under the Air Force-sponsored Design Methods for Integrated Control Systems program. This goal was achieved by exercising the design methodology for the linear point design presented in this paper. The control system design was performed for the piloted longitudinal landing task of a modern, statically unstable fighter aircraft, powered by a two 
spool turbofan engine and equipped with a 2D thrust vectoring nozzle. The results of this study lead to the following summary of the strengths and weaknesses of the linear design portion of this methodology:

\section{Strengths}

1) This hierarchical approach results in lower order subsystems with easy to implement subcontrollers, compared to a single, global compensator. This approach allows system specialists to work in their area of expertise. Also, the selection of design criteria for the separate partitions is simplified, when compared to the selection of design criteria for a global LQR design approach.

2) The use of generalized controls is unique and relieves the pilot from the task of distributing moment and thrust requirements among the available effectors. The use of generalized controls may also reduce the number of gains required to be scheduled when the control is in full flight envelope operation.

\section{Weaknesses}

1) The procedure does not consider the airframe-to-engine coupling in the linear portion of the design. Therefore, the methodology may require modifications to ensure the stability of the integrated systems on future V/STOL applications with stronger airframe-to-engine coupling.

2) Estimates of the propulsive moments and forces were assumed to be available for the engine feedback control system. The quality of these estimates is untested and needs to be evaluated in terms of accuracy and stability when implemented.

3) The method requires many steps and could lead to a highly iterative design if the specifications for the low-level subsystem are not satisfied.

4) The design of the control selector was simplified to a constant gain matrix in the example discussed in this paper. The design of a general control selector capable of handing the entire flight envelope would be a more difficult task. 
A discussion of the current IFPC research program that will evaluate this methodology for a more strongly coupled system over a wider flight envelope appears in reference [3]. This program will also evaluate the use of thrust estimation for propulsion control.

\section{Appendix}

\section{Derivation of Linear System Matrix Partitioning}

The following describes the derivation of the solution to the partitioning problem using the minimization of the least square matrix element error criterion. The transformation from $(3 \& 4)$ to $(1 \& 2)$ results in 16 equations in 16 unknowns and can be solved with simple matrix algebra. The mapping is one-to-one (assuming the inverses below exist), and offers the unique solution shown below:

$$
\begin{aligned}
& \mathrm{M}=\left(\mathrm{I}-\mathrm{W}_{\mathrm{ea}} \mathrm{V}_{\mathrm{a}} \mathrm{W}_{\mathrm{ae}} \mathrm{V}_{\mathrm{e}}\right)^{-1} \quad \text { and } \quad \mathrm{N}=\left(\mathrm{I}-\mathrm{W}_{\mathrm{ae}} \mathrm{V}_{\mathrm{e}} \mathrm{W}_{\mathrm{ea}} \mathrm{V}_{\mathrm{a}}\right)^{-1} \\
& \text { Note that: } \mathrm{NW}_{\mathrm{ae}} \mathrm{V}_{\mathrm{e}}=\mathrm{W}_{\mathrm{ae}} \mathrm{V}_{\mathrm{e}} \mathrm{M} \text { and } \mathrm{MW}_{\mathrm{ea}} \mathrm{V}_{\mathrm{a}}=\mathrm{W}_{\mathrm{ea}} \mathrm{V}_{\mathrm{a}} \mathrm{N} \\
& \mathrm{C}_{11}=\quad \mathrm{NC}_{\mathrm{a}} \quad \mathrm{C}_{22}=\mathrm{MC}_{\mathrm{e}} \\
& \mathrm{C}_{12}=\mathrm{NW}_{\mathrm{ae}} \mathrm{V}_{\mathrm{e}} \mathrm{C}_{\mathrm{e}}=\mathrm{W}_{\mathrm{ae}} \mathrm{V}_{\mathrm{e}} \mathrm{MC}_{\mathrm{e}}=\mathrm{W}_{\mathrm{ae}} \mathrm{V}_{\mathrm{e}} \mathrm{C}_{22} \\
& \mathrm{C}_{21}=\mathrm{MW}_{\mathrm{ea}} \mathrm{V}_{\mathrm{a}} \mathrm{C}_{\mathrm{a}}=\mathrm{W}_{\mathrm{ea}} \mathrm{V}_{\mathrm{a}} \mathrm{NC}_{\mathrm{a}}=\mathrm{W}_{\mathrm{ea}} \mathrm{V}_{\mathrm{a}} \mathrm{C}_{11} \\
& \mathrm{D}_{11}=\quad \mathrm{ND}_{\mathrm{a}} \quad \mathrm{D}_{22}=\mathrm{MD}_{\mathrm{e}} \\
& D_{12}=N W_{a e} V_{e} D_{e}=W_{a c} V_{e} M D_{e}=W_{a c} V_{e} D_{22} \\
& \mathrm{D}_{21}=M \mathrm{~W}_{\mathrm{ea}} \mathrm{V}_{\mathrm{a}} \mathrm{D}_{\mathrm{a}}=\mathrm{W}_{\mathrm{ea}} \mathrm{V}_{\mathrm{a}} \mathrm{ND}_{\mathrm{a}}=\mathrm{W}_{\mathrm{ea}} \mathrm{V}_{\mathrm{a}} \mathrm{D}_{11}
\end{aligned}
$$




$$
\begin{aligned}
& A_{11}=A_{a}+\Gamma_{a e} V_{e} M_{e a} V_{a} C_{a}=A_{a}+\Gamma_{a e} V_{e} C_{21} \\
& A_{12}=\Gamma_{\mathrm{ae}} \mathrm{V}_{\mathrm{e}} \mathrm{MC}_{\mathrm{e}} \quad \mathrm{A}_{21}=\Gamma_{\mathrm{ea}} \mathrm{V}_{\mathrm{a}} \mathrm{NC}_{\mathrm{a}} \\
& \mathrm{A}_{22}=\mathrm{A}_{\mathrm{e}}+\Gamma_{\mathrm{ea}} \mathrm{V}_{\mathrm{a}} \mathrm{NW}_{\mathrm{ae}} \mathrm{V}_{\mathrm{e}} \mathrm{C}_{\mathrm{e}}=\mathrm{A}_{\mathrm{e}}+\Gamma_{\mathrm{ea}} \mathrm{V}_{\mathrm{a}} \mathrm{C}_{12} \\
& \mathrm{~B}_{11}=\mathrm{B}_{\mathrm{a}}+\Gamma_{\mathrm{ac}} \mathrm{V}_{\mathrm{e}} \mathrm{MW} \mathrm{Wa}_{\mathrm{a}} \mathrm{V}_{\mathrm{a}}=\mathrm{B}_{\mathrm{a}}+\Gamma_{\mathrm{ae}} \mathrm{V}_{\mathrm{e}} \mathrm{D}_{21} \\
& \mathrm{~B}_{12}=\Gamma_{\mathrm{ac}} \mathrm{V}_{\mathrm{e}} \mathrm{MD}_{\mathrm{e}} \quad \mathrm{B}_{21}=\Gamma_{\mathrm{ea}} \mathrm{V}_{\mathrm{a}} \mathrm{ND}_{\mathrm{a}} \\
& \mathrm{B}_{22}=\mathrm{B}_{\mathrm{e}}+\Gamma_{\mathrm{ea}} \mathrm{V}_{\mathrm{a}} \mathrm{NW}_{\mathrm{ae}} \mathrm{V}_{\mathrm{e}} \mathrm{D}_{\mathrm{e}}=\mathrm{B}_{\mathrm{e}}+\Gamma_{\mathrm{ea}} \mathrm{V}_{\mathrm{a}} \mathrm{D}_{12}
\end{aligned}
$$

The inverse of this mapping results in 16 equations in 12 unknowns. Eight of the equations can be combined to yield 4 constraint equations. The defining equations for the mapping from $(1 \& 2)$ to $(3 \& 4)$ are shown below along with the least square solution to the constraint equations:

$$
\begin{array}{ll}
\mathrm{A}_{\mathrm{a}}=\mathrm{A}_{11}-\Gamma_{\mathrm{ae}} \mathrm{V}_{\mathrm{e}} \mathrm{C}_{21} & \mathrm{~B}_{\mathrm{a}}=\mathrm{B}_{11}-\Gamma_{\mathrm{ae}} \mathrm{V}_{\mathrm{e}} \mathrm{D}_{21} \\
\mathrm{C}_{\mathrm{a}}=\mathrm{C}_{11}-\mathrm{W}_{\mathrm{ae}} \mathrm{V}_{\mathrm{e}} \mathrm{C}_{21} & \mathrm{D}_{\mathrm{a}}=\mathrm{D}_{11}-\mathrm{W}_{\mathrm{ae}} \mathrm{V}_{\mathrm{e}} \mathrm{D}_{21} \\
\mathrm{~A}_{\mathrm{e}}=\mathrm{A}_{22}-\Gamma_{\mathrm{ea}} \mathrm{V}_{\mathrm{a}} \mathrm{C}_{12} & \mathrm{~B}_{\mathrm{e}}=\mathrm{B}_{22}-\Gamma_{\mathrm{ea}} \mathrm{V}_{\mathrm{a}} \mathrm{D}_{12} \\
\mathrm{C}_{\mathrm{e}}=\mathrm{C}_{22}-\mathrm{W}_{\mathrm{ea}} \mathrm{V}_{\mathrm{a}} \mathrm{C}_{12} & \mathrm{D}_{\mathrm{e}}=\mathrm{D}_{22}-\mathrm{W}_{\mathrm{ea}} \mathrm{V}_{\mathrm{a}} \mathrm{D}_{12}
\end{array}
$$

Least Square Solution of 4 Constraints

$$
\begin{aligned}
& A_{12}=\Gamma_{a e} V_{e} C_{22} \quad B_{12}=\Gamma_{a e} V_{e} D_{22} \quad \Gamma_{a e}=\left[B_{12} A_{12}\right] \cdot\left\{V_{e}\left[D_{22} C_{22}\right]\right\}^{\#} \\
& \mathrm{C}_{12}=\mathrm{W}_{\mathrm{ae}} \mathrm{V}_{\mathrm{e}} \mathrm{C}_{22} \quad \mathrm{D}_{12}=\mathrm{W}_{\mathrm{ae}} \mathrm{V}_{\mathrm{e}} \mathrm{D}_{22} \quad \mathrm{~W}_{\mathrm{ac}}=\left[\mathrm{D}_{12} \mathrm{C}_{12}\right] \cdot\left\{\mathrm{V}_{\mathrm{e}}\left[\mathrm{D}_{22} \mathrm{C}_{22}\right]\right\}^{\#} \\
& A_{21}=\Gamma_{e a} V_{a} C_{11} \quad B_{21}=\Gamma_{e a} V_{a} D_{11} \quad \Gamma_{e a}=\left[B_{21} A_{21}\right] \cdot\left\{V_{a}\left[D_{11} C_{11}\right]\right\}^{\#} \\
& \mathrm{C}_{21}=\mathrm{W}_{\mathrm{ea}} \mathrm{V}_{\mathrm{a}} \mathrm{C}_{11} \quad \mathrm{D}_{21}=\mathrm{W}_{\mathrm{ea}} \mathrm{V}_{\mathrm{a}} \mathrm{D}_{11} \quad \mathrm{~W}_{\mathrm{ea}}=\left[\mathrm{D}_{21} \mathrm{C}_{21}\right] \cdot\left\{\mathrm{V}_{\mathrm{a}}\left[\mathrm{D}_{11} \mathrm{C}_{11}\right]\right\}^{\#}
\end{aligned}
$$

The solutions in (A.3) can be used to solve (A.2) for $A_{a}, B_{a}, C_{a}, D_{a}, A_{e}, B_{e}, C_{e}$, and $D_{e}$. These solutions are dependent on the $\mathrm{C}_{\mathrm{ij}}$ and $\mathrm{D}_{\mathrm{ij}}$ matrices, and on the set of outputs selected to represent the coupling interface, defined by $\mathrm{V}_{\mathrm{a}}$ and $\mathrm{V}_{\mathrm{e}}$. Thus, once the interface variables are selected, the structure in (1\&2) is transformed into the structure in (3\&4) using (A.2, 
A.3) above. The accuracy of this transformation is checked by transforming the resulting structure in (3\&4) back to the structure in (1\&2) using (A.1). By comparing the results of this retransformation to the original matrices the individual matrix element errors can be identified. If the errors are "reasonably small" and the system eigenvalues and eigenvectors are insensitive to these errors, then the transformation is successful and the structure in $(3 \& 4)$ is a valid representation of the dynamics system in $(1 \& 2)$. This scheme worked reasonably well for the example presented here, but, in general, a more detailed analysis will be required. Current research in $\mathrm{H}_{\infty}$ optimization is applicable to this model matching problem and should result in a more general technique.

Integrated System Matrices Required for Partitioning

$\begin{array}{ll}6 \text { inputs } & \mathrm{u}=\delta_{\mathrm{FLE}}, \delta_{\mathrm{FTE}}, \mathrm{WF} 36, \mathrm{~A} 78, \mathrm{~A} 8, \delta_{\mathrm{TV}} \\ 8 \text { outputs } & \mathrm{y}=\mathrm{V}, \gamma, \mathrm{q}, \theta, \mathrm{h}, \mathrm{F}_{\mathrm{ex}}, \mathrm{F}_{\mathrm{ez}}, \mathrm{T} \\ 9 \text { th order state vector } & \mathrm{x}=\mathrm{u}, \mathrm{w}, \mathrm{q}, \theta, \mathrm{h} \mathrm{N} 2, \mathrm{~N} 25, \mathrm{P} 6, \mathrm{~T} 41 \mathrm{~B}\end{array}$

$A_{p}=$

COLUMNS 1 THRU 6

$-5.8927 \mathrm{e}-02 \quad 1.0675 \mathrm{e}-01-3.8598 \mathrm{e}+01-3.1839 \mathrm{e}+01 \quad 1.4098 \mathrm{e}-02 \quad 3.1445 \mathrm{e}-04$

$-2.6588 \mathrm{e}-01-2.6652 \mathrm{e}-01 \quad 1.9481 \mathrm{e}+02-4.5989 \mathrm{e}+00 \quad 5.1963 \mathrm{e}-04-1.5785 \mathrm{e}-05$

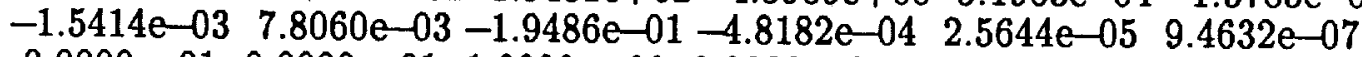

$\begin{array}{llllll}0.0000 \mathrm{e}-01 & 0.0000 \mathrm{e}-01 & 1.0000 \mathrm{e}+00 & 0.0000 \mathrm{e}-01 & 0.0000 \mathrm{e}-01 & 0.0000 \mathrm{e}-01\end{array}$

$\begin{array}{llllll}1.4275 \mathrm{e}-01 & -9.8976 \mathrm{e}-01 & 0.0000 \mathrm{e}-01 & 2.0060 \mathrm{e}+02 & 0.0000 \mathrm{e}-01 & 0.0000 \mathrm{e}-01\end{array}$

$\begin{array}{lllll}7.7818 \mathrm{e}-01 & 1.5424 \mathrm{e}-01 & 0.0000 \mathrm{e}-01 & 0.0000 \mathrm{e}-01-8.4851 \mathrm{e}-02 & -4.1914 \mathrm{e}+00\end{array}$

$\begin{array}{llllll}1.5179 \mathrm{e}-01 & 3.0085 \mathrm{e}-02 & 0.0000 \mathrm{e}-01 & 0.0000 \mathrm{e}-01-1.6551 \mathrm{e}-02 & 4.2632 \mathrm{e}-01\end{array}$

$\begin{array}{llllll}7.9337 \mathrm{e}-01 & 1.5725 \mathrm{e}-01 & 0.0000 \mathrm{e}-01 & 0.0000 \mathrm{e}-01 & -3.5024 \mathrm{e}-01 & 2.2953 \mathrm{e}-01\end{array}$

$\begin{array}{llllll}-1.0053 e-01 & -1.9925 e-02 & 0.0000 e-01 & 0.0000 e-01 & 1.0962 e-02 & 3.7401 e-02\end{array}$

\begin{tabular}{ccc}
\multicolumn{5}{c}{ COLUMNS } & 7 THRU 9 \\
$2.5989 \mathrm{e}-04$ & $3.8186 \mathrm{e}-02$ & $2.2508 \mathrm{e}-03$ \\
$-2.1058 \mathrm{e}-06$ & $1.8261 \mathrm{e}-04$ & $-2.9567 \mathrm{e}-06$ \\
$3.7441 \mathrm{e}-07$ & $3.6678 \mathrm{e}-05$ & $2.6732 \mathrm{e}-06$ \\
$0.0000 \mathrm{e}-01$ & $0.0000 \mathrm{e}-01$ & $0.0000 \mathrm{e}-01$ \\
$0.0000 \mathrm{e}-01$ & $0.0000 \mathrm{e}-01$ & $0.0000 \mathrm{e}-01$ \\
$6.0216 \mathrm{e}+00$ & $-3.4337 \mathrm{e}+02$ & $1.1603 \mathrm{e}+01$ \\
$-5.7070 \mathrm{e}+00$ & $2.7163 \mathrm{e}+01$ & $1.0396 \mathrm{e}+01$ \\
$1.1548 \mathrm{e}-01$ & $-9.0238 \mathrm{e}+01$ & $8.4760 \mathrm{e}-01$ \\
$-1.0362 \mathrm{e}-01$ & $-7.9538 \mathrm{e}+00$ & $-1.0682 \mathrm{e}+00$
\end{tabular}




$$
\begin{aligned}
& \mathrm{B}_{\mathrm{p}}=\quad 3.4680 \mathrm{e}-02-4.9602 \mathrm{e}-02 \quad 3.4360 \mathrm{e}-05-2.0546 \mathrm{e}-01 \quad 6.9121 \mathrm{e}-02-4.1834 \mathrm{e}-04 \\
& 6.9252 \mathrm{e}-02-1.4550 \mathrm{e}-01 \quad 1.2340 \mathrm{e}-08-2.9360 \mathrm{e}-04 \quad 7.1041 \mathrm{e}-05-5.4520 \mathrm{e}-01 \\
& -8.1002 \mathrm{e}-03 \quad 7.1325 \mathrm{e}-04 \quad 5.5072 \mathrm{e}-08 \quad 1.0677 \mathrm{e}-04-8.3833 \mathrm{e}-05-7.9733 \mathrm{e}-02 \\
& \begin{array}{lllllll}
0.0000 \mathrm{e}-01 & 0.0000 \mathrm{e}-01 & 0.0000 \mathrm{e}-01 & 0.0000 \mathrm{e}-01 & 0.0000 \mathrm{e}-01 & 0.0000 \mathrm{e}-01
\end{array} \\
& \begin{array}{lllllll}
0.0000 \mathrm{e}-01 & 0.0000 \mathrm{e}-01 & 0.0000 \mathrm{e}-01 & 0.0000 \mathrm{e}-01 & 0.0000 \mathrm{e}-01 & 0.0000 \mathrm{e}-01
\end{array} \\
& \begin{array}{lllllll}
0.0000 \mathrm{e}-01 & 0.0000 \mathrm{e}-01 & 1.4694 \mathrm{e}-01 & 0.0000 \mathrm{e}-01 & 0.0000 \mathrm{e}-01 & 0.0000 \mathrm{e}-01
\end{array} \\
& \begin{array}{lllllll}
0.0000 \mathrm{e}-01 & 0.0000 \mathrm{e}-01 & 5.3656 \mathrm{e}-02 & 0.0000 \mathrm{e}-01 & 0.0000 \mathrm{e}-01 & 0.0000 \mathrm{e}-01
\end{array} \\
& 0.0000 \mathrm{e}-01 \quad 0.0000 \mathrm{e}-01 \quad 1.8127 \mathrm{e}-02-4.3021 \mathrm{e}+01-2.5835 \mathrm{e}+01 \quad 0.0000 \mathrm{e}-01 \\
& 0.0000 \mathrm{e}-01 \quad 0.0000 \mathrm{e}-01 \quad 1.6430 \mathrm{e}-01 \quad 0.0000 \mathrm{e}-01 \quad 0.0000 \mathrm{e}-01 \quad 0.0000 \mathrm{e}-01
\end{aligned}
$$$$
\mathrm{C}_{\mathrm{p}}=\quad \text { COLUMNS } 1 \text { THRU } 6
$$

$\begin{array}{llllll}9.7971 \mathrm{e}-01 & 1.9412 \mathrm{e}-01 & 0.0000 \mathrm{e}-01 & 0.0000 \mathrm{e}-01 & 0.0000 \mathrm{e}-01 \quad 0.0000 \mathrm{e}-01\end{array}$

$\begin{array}{llllll}5.8883 \mathrm{e}-02-2.7958 \mathrm{e}-01 & 0.0000 \mathrm{e}-01 & 5.7296 \mathrm{e}+01 & 0.0000 \mathrm{e}-01 & 0.0000 \mathrm{e}-01\end{array}$

$\begin{array}{lllllll}0.0000 \mathrm{e}-01 & 0.0000 \mathrm{e}-01 & 5.7296 \mathrm{e}+01 & 0.0000 \mathrm{e}-01 & 0.0000 \mathrm{e}-01 & 0.0000 \mathrm{e}-01\end{array}$

$\begin{array}{llllll}0.0000 \mathrm{e}-01 & 0.0000 \mathrm{e}-01 & 0.0000 \mathrm{e}-01 & 5.7296 \mathrm{e}+01 & 0.0000 \mathrm{e}-01 & 0.0000 \mathrm{e}-01\end{array}$

$\begin{array}{llllll}0.0000 \mathrm{e}-01 & 0.0000 \mathrm{e}-01 & 0.0000 \mathrm{e}-01 & 0.0000 \mathrm{e}-01 & 1.0000 \mathrm{e}+00 & 0.0000 \mathrm{e}-01\end{array}$

$\begin{array}{llllll}1.2147 \mathrm{e}+00 & 2.4076 \mathrm{e}-01 & 0.0000 \mathrm{e}-01 & 0.0000 \mathrm{e}-01 & 1.2048 \mathrm{e}+01 & 3.4557 \mathrm{e}-01\end{array}$

$-2.7442 \mathrm{e}-03-5.4390 \mathrm{e}-04 \quad 0.0000 \mathrm{e}-01 \quad 0.0000 \mathrm{e}-01-4.1640 \mathrm{e}-02-7.4322 \mathrm{e}-04$

$2.7487 \mathrm{e}-01 \quad 5.4480 \mathrm{e}-02 \quad 0.0000 \mathrm{e}-01 \quad 0.0000 \mathrm{e}-01 \quad 2.2269 \mathrm{e}+00 \quad 8.1022 \mathrm{e}-02$

COLUMNS 7 THRU 9

$0.0000 \mathrm{e}-01 \quad 0.0000 \mathrm{e}-01 \quad 0.0000 \mathrm{e}-01$

$0.0000 \mathrm{e}-01 \quad 0.0000 \mathrm{e}-01 \quad 0.0000 \mathrm{e}-01$

$0.0000 \mathrm{e}-01 \quad 0.0000 \mathrm{e}-01 \quad 0.0000 \mathrm{e}-01$

$0.0000 \mathrm{e}-01 \quad 0.0000 \mathrm{e}-01 \quad 0.0000 \mathrm{e}-01$

$0.0000 \mathrm{e}-01 \quad 0.0000 \mathrm{e}-01 \quad 0.0000 \mathrm{e}-01$

$2.3118 \mathrm{e}-01 \quad 3.1521 \mathrm{e}+01 \quad 1.9262 \mathrm{e}+00$

$-8.3705 \mathrm{e}-04-1.3301 \mathrm{e}-01-7.5608 \mathrm{e}-03$

$2.8577 \mathrm{e}-02 \quad 2.4726 \mathrm{e}+00 \quad 1.9388 \mathrm{e}-01$

$\mathrm{D}_{\mathrm{p}}=0.0000 \mathrm{e}-01 \quad 0.0000 \mathrm{e}-01 \quad 0.0000 \mathrm{e}-01 \quad 0.0000 \mathrm{e}-01 \quad 0.0000 \mathrm{e}-01 \quad 0.0000 \mathrm{e}-01$

$\begin{array}{lllllll}0.0000 \mathrm{e}-01 & 0.0000 \mathrm{e}-01 & 0.0000 \mathrm{e}-01 & 0.0000 \mathrm{e}-01 & 0.0000 \mathrm{e}-01 & 0.0000 \mathrm{e}-01\end{array}$

$\begin{array}{lllllll}0.0000 \mathrm{e}-01 & 0.0000 \mathrm{e}-01 & 0.0000 \mathrm{e}-01 & 0.0000 \mathrm{e}-01 & 0.0000 \mathrm{e}-01 & 0.0000 \mathrm{e}-01\end{array}$

$\begin{array}{llllll}0.0000 \mathrm{e}-01 & 0.0000 \mathrm{e}-01 & 0.0000 \mathrm{e}-01 & 0.0000 \mathrm{e}-01 & 0.0000 \mathrm{e}-01 & 0.0000 \mathrm{e}-01\end{array}$

$\begin{array}{llllll}0.0000 \mathrm{e}-01 & 0.0000 \mathrm{e}-01 & 0.0000 \mathrm{e}-01 & 0.0000 \mathrm{e}-01 & 0.0000 \mathrm{e}-01 & 0.0000 \mathrm{e}-01\end{array}$

$0.0000 \mathrm{e}-01 \quad 0.0000 \mathrm{e}-01 \quad 2.9552 \mathrm{e}-02-1.7079 \mathrm{e}+02 \quad 5.6842 \mathrm{e}+01 \quad 0.0000 \mathrm{e}-01$

$0.0000 \mathrm{e}-01 \quad 0.0000 \mathrm{e}-01-9.3010 \mathrm{e}-05-2.8600 \mathrm{e}-01 \quad 1.4822 \mathrm{e}-01-4.5932 \mathrm{e}+02$

$0.0000 \mathrm{e}-01 \quad 0.0000 \mathrm{e}-01 \quad 4.7079 \mathrm{e}-03 \quad 9.6000 \mathrm{e}+00-7.8168 \mathrm{e}+00-9.3011 \mathrm{e}+03$

Scaling Matrices used for partitioning

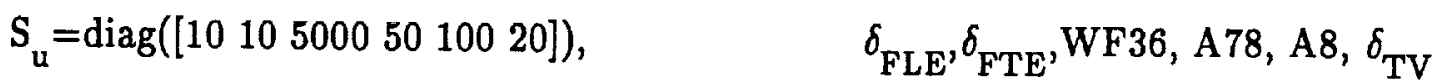

$$
\begin{aligned}
& \mathrm{S}_{\mathrm{y}}=\operatorname{diag}([20,4.5,4.5,4.0,20,4000,400,10000]), \quad \mathrm{V}, \gamma, \mathrm{q}, 0, \mathrm{~h}, \mathrm{~F}_{\mathrm{ex}} \mathrm{F}_{\text {ez }} \mathrm{T}_{\mathrm{em}} \\
& S_{x}=\operatorname{diag}([20,25,0.0785,0.070,100,573,727,30,50]), \quad u, w, q, \theta, h, N 2, N 25, P 6, T 41 B
\end{aligned}
$$




\section{Airframe Partition System Matrices}

\section{5 inputs}

5 outputs

5 th order state vector

$$
\begin{aligned}
& \mathrm{u}_{\mathrm{a}}=\delta_{\mathrm{FLE}}, \delta_{\mathrm{FTE}}, \mathrm{F}_{\mathrm{ex}}, \mathrm{F}_{\mathrm{ez}}, \mathrm{T}_{\mathrm{em}} \\
& \mathrm{z}_{\mathrm{a}}=\mathrm{V}, \gamma, \mathrm{q}, \theta, \mathrm{h} \\
& \mathrm{x}_{\mathrm{a}}=\mathrm{u}, \mathrm{w}, \mathrm{q}, \theta, \mathrm{h}
\end{aligned}
$$

$\left[\mathrm{B}_{\mathrm{a}} \Gamma_{\mathrm{ae}}\right]=3.4680 \mathrm{e}-02-4.9602 \mathrm{e}-02 \quad 1.2026 \mathrm{e}-03 \quad 4.2499 \mathrm{e}-04-2.0943 \mathrm{e}-05$

$6.9252 \mathrm{e}-02-1.4550 \mathrm{e}-01 \quad 3.0735 \mathrm{e}-06 \quad 4.9203 \mathrm{e}-04 \quad 3.4319 \mathrm{e}-05$

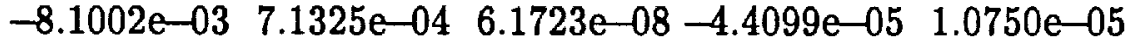

$\begin{array}{llllll}0.0000 \mathrm{e}+00 & 0.0000 \mathrm{e}+00 & 0.0000 \mathrm{e}+00 & 0.0000 \mathrm{e}+00 & 0.0000 \mathrm{e}+00\end{array}$

$\begin{array}{lllll}0.0000 \mathrm{e}+00 & 0.0000 \mathrm{e}+00 & 0.0000 \mathrm{e}+00 & 0.0000 \mathrm{e}+00 & 0.0000 \mathrm{e}+00\end{array}$

$\mathrm{C}_{\mathrm{a}}=\quad-8.8495 \mathrm{e}-02 \quad 4.4721 \mathrm{e}-01-1.1165 \mathrm{e}+01-2.7606 \mathrm{e}-02-5.0150 \mathrm{e}-05$

$\begin{array}{lllll}0.0000 \mathrm{e}+00 & 0.0000 \mathrm{e}+00 & 5.7296 \mathrm{e}+01 & 0.0000 \mathrm{e}+00 & 0.0000 \mathrm{e}+00\end{array}$

$\begin{array}{lllll}0.0000 \mathrm{e}+00 & 0.0000 \mathrm{e}+00 & 0.0000 \mathrm{e}+00 & 5.7296 \mathrm{e}+01 & 0.0000 \mathrm{e}+00\end{array}$

$7.0783 \mathrm{e}-02 \quad 8.0783 \mathrm{e}-02 \quad 5.5794 \mathrm{e}-01-5.8901 \mathrm{e}-01-1.3848 \mathrm{e}-04$

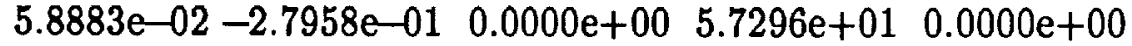

$-1.1077 \mathrm{e}-01 \quad 5.2564 \mathrm{e}-02 \quad 1.6706 \mathrm{e}-03-3.2086 \mathrm{e}+01-2.3647 \mathrm{e}-04$

$\begin{array}{lllll}9.7971 \mathrm{e}-01 & 1.9412 \mathrm{e}-01 & 0.0000 \mathrm{e}+00 & 0.0000 \mathrm{e}+00 & 0.0000 \mathrm{e}+00\end{array}$

$\left[\mathrm{D}_{\mathrm{a}} \mathrm{W}_{\mathrm{ae}}\right]=-4.6411 \mathrm{e}-01 \quad 4.0866 \mathrm{e}-02 \quad 3.5365 \mathrm{e}-06-2.5267 \mathrm{e}-03 \quad 6.1594 \mathrm{e}-04$

$\begin{array}{llllllllll}0.0000 \mathrm{e}+00 & 0.0000 \mathrm{e}+00 & 0.0000 \mathrm{e}+00 & 0.0000 \mathrm{e}+00 & 0.0000 \mathrm{e}+00\end{array}$

$\begin{array}{llllllll}0.0000 \mathrm{e}+00 & 0.0000 \mathrm{e}+00 & 0.0000 \mathrm{e}+00 & 0.0000 \mathrm{e}+00 & 0.0000 \mathrm{e}+00\end{array}$

$-1.7320 \mathrm{e}-02 \quad 3.7759 \mathrm{e}-02 \quad 6.9951 \mathrm{e}-05-1.1254 \mathrm{e}-04-1.0828 \mathrm{e}-05$

$\begin{array}{lllllll}0.0000 \mathrm{e}+00 & 0.0000 \mathrm{e}+00 & 0.0000 \mathrm{e}+00 & 0.0000 \mathrm{e}+00 & 0.0000 \mathrm{e}+00\end{array}$

$4.7420 \mathrm{e}-02-7.6840 \mathrm{e}-02 \quad 1.1788 \mathrm{e}-03 \quad 5.1188 \mathrm{e}-04-1.3856 \mathrm{e}-05$

$\begin{array}{lllllll}0.0000 \mathrm{e}+00 & 0.0000 \mathrm{e}+00 & 0.0000 \mathrm{e}+00 & 0.0000 \mathrm{e}+00 & 0.0000 \mathrm{e}+00\end{array}$ 
Propulsion Partition System Variables

$\begin{array}{ll}4 \text { inputs } & \mathrm{u}_{\mathrm{e}}=\mathrm{WF} 36, \mathrm{~A} 78, \mathrm{~A} 8, \delta_{\mathrm{TV}} \\ 5 \text { coupling inputs } & \mathrm{z}_{\mathrm{a}}=\mathrm{V}, \gamma, \mathrm{q}, \theta, \mathrm{h} \\ 3 \text { outputs } & \mathrm{z}_{\mathrm{e}}=\mathrm{F}_{\mathrm{ex}}, \mathrm{F}, \mathrm{ez}, \mathrm{T}_{\mathrm{em}} \\ 4 \text { th order state vector } & \mathrm{x}_{\mathrm{e}}=\mathrm{N} 2, \mathrm{~N} 25, \mathrm{P} 6, \mathrm{~T} 41 \mathrm{~b}\end{array}$

$$
\begin{aligned}
& \mathrm{A}_{\mathrm{e}}=-4.1914 \mathrm{e}+00 \quad 6.0216 \mathrm{e}+00-3.4337 \mathrm{e}+02 \quad 1.1603 \mathrm{e}+01 \\
& \begin{array}{llll}
4.2632 \mathrm{e}-01 & -5.7070 \mathrm{e}+00 & 2.7163 \mathrm{e}+01 & 1.0396 \mathrm{e}+01
\end{array} \\
& 2.2953 \mathrm{e}-01 \quad 1.1548 \mathrm{e}-01-9.0238 \mathrm{e}+01 \quad 8.4760 \mathrm{e}-01 \\
& 3.7401 \mathrm{e}-02-1.0362 \mathrm{e}-01-7.9538 \mathrm{e}+00-1.0682 \mathrm{e}+00 \\
& \mathrm{~B}_{\mathrm{e}}=1.4694 \mathrm{e}-01 \quad 0.0000 \mathrm{e}-01 \quad 0.0000 \mathrm{e}-01 \quad 0.0000 \mathrm{e}-01 \\
& \begin{array}{lllll}
5.3656 \mathrm{e}-02 & 0.0000 \mathrm{e}-01 & 0.0000 \mathrm{e}-01 & 0.0000 \mathrm{e}-01
\end{array} \\
& 1.8127 \mathrm{e}-02-4.3021 \mathrm{e}+01-2.5835 \mathrm{e}+01 \quad 0.0000 \mathrm{e}-01 \\
& \begin{array}{llll}
1.6430 \mathrm{e}-01 & 0.0000 \mathrm{e}-01 & 0.0000 \mathrm{e}-01 & 0.0000 \mathrm{e}-01
\end{array} \\
& \mathrm{C}_{\mathrm{e}}=3.4557 \mathrm{e}-01 \quad 2.3118 \mathrm{e}-01 \quad 3.1521 \mathrm{e}+01 \quad 1.9262 \mathrm{e}+00 \\
& -7.4322 \mathrm{e}-04-8.3705 \mathrm{e}-04-1.3301 \mathrm{e}-01-7.5608 \mathrm{e}-03 \\
& \begin{array}{llll}
8.1022 \mathrm{e}-02 & 2.8577 \mathrm{e}-02 & 2.4726 \mathrm{e}+00 & 1.9388 \mathrm{e}-01
\end{array}
\end{aligned}
$$$$
\mathrm{D}_{\mathrm{e}}=2.9552 \mathrm{e}-02-1.7079 \mathrm{e}+02 \quad 5.6842 \mathrm{e}+01 \quad 0.0000 \mathrm{e}-01
$$$$
-9.3010 \mathrm{e}-05-2.8600 \mathrm{e}-01 \quad 1.4822 \mathrm{e}-01-4.5932 \mathrm{e}+02
$$$$
4.7079 \mathrm{e}-03 \quad 9.6000 \mathrm{e}+00-7.8168 \mathrm{e}+00-9.3011 \mathrm{e}+03
$$$$
\Gamma_{\text {ea }}=7.9431 \mathrm{e}-01 \quad-1.7582 \mathrm{e}-04 \quad 0.0000 \mathrm{e}-01 \quad 1.7582 \mathrm{e}-04-8.4851 \mathrm{e}-02
$$$$
1.5494 \mathrm{e}-01-3.0177 \mathrm{e}-05 \quad 0.0000 \mathrm{e}-01 \quad 3.0177 \mathrm{e}-05-1.6551 \mathrm{e}-02
$$$$
8.0981 \mathrm{e}-01-1.7668 \mathrm{e}-04 \quad 0.0000 \mathrm{e}-01 \quad 1.7668 \mathrm{e}-04-3.5024 \mathrm{e}-01
$$$$
\begin{array}{llll}
-1.0261 \mathrm{e}-01 & 2.0460 \mathrm{e}-05 & 0.0000 \mathrm{e}-01-2.0460 \mathrm{e}-05 & 1.0962 \mathrm{e}-02
\end{array}
$$

$$
\begin{aligned}
& \mathrm{W}_{\text {ea }}=1.2399 \mathrm{e}+00-2.7131 \mathrm{e}-04 \quad 0.0000 \mathrm{e}-01 \quad 2.7131 \mathrm{e}-04 \quad 1.2048 \mathrm{e}+01 \\
& -2.8011 \mathrm{e}-03 \quad 5.6481 \mathrm{e}-07 \quad 0.0000 \mathrm{e}-01-5.6481 \mathrm{e}-07-4.1640 \mathrm{e}-02 \\
& \begin{array}{lllll}
2.8057 \mathrm{e}-01 & -5.7632 \mathrm{e}-05 & 0.0000 \mathrm{e}-01 & 5.7632 \mathrm{e}-05 & 2.2269 \mathrm{e}+00
\end{array}
\end{aligned}
$$

\section{Acknowledgement}

The authors would like to thank Mr. Kevin Madden and Dr. P.D. Shaw, Flight Control Research Dept., Northrop Corp., Hawthorne, CA., for having provided the linearized aircraft model used in this study. 


\section{References}

[1] Shaw,P.D., Rock, S.M., and Fisk, W.S., "Design Methods for Integrated Control Systems", AFWAL-TR-88-2061, Wright Patterson AFB, Dayton OH, June 1988.

[2] Smith, K.L., "Design Methods for Integrated Control Systems", AFWAL-TR-860-2103, Wright Patterson AFB, Dayton, OH, Dec. 1986.

[3] Mihaloew, J., "Flight Propulsion Control Integration for V/STOL Aircraft", NASA TM-100226, Dec. 1987.

[4] Rock, S.M., Emami-Naeini, A., and Anex, R.P., "Propulsion Control Specifications in Integrated Flight/Propulsion Control Systems", AIAA-88-3236, 24th Joint Propulsion Conference, July 11, 1988.

[5] Kwakernaak, H., Sivan, R., "Linear Optimal Control Systems", Wiley Interscience, 1972, p. 253-265.

[6] "Multi-Input Multi-Output System Control for Experimental Aircraft", NASA-CR-181197, Purdue University School of Aeronautics and Astronautics Report N37-26915.

[7] Garg, S., Mattern, D., and Bullard, R.E., "Integrated Flight/Propulsion Control System Design Based on a Centralized Approach", AIAA Guidance, Navigation and Control Conference, AIAA 89-3520, Boston MA, August 1989.

[8] "Military Specification - Flying Qualities of Piloted Airplanes", MIL-F-8785C, USAF, Wright Patterson AFB, OH, Nov., 1980.

[9] McRuer,D., Ashkenas,I., and Graham, D., "Aircraft Dynamics and Automatic Control", Princeton University Press, Princeton, NJ, 1973.

[10] US/Canada STOVL Technology Program, Monthly Technical Narrative No. 15, December 1988, by General Electric for NASA Contract NAS3-25193.

[11] Lehtomaki, N.A., Sandell Jr., N.R., and Athans, M., "Robustness Results in LQG-Based Multivariable Control Design", IEEE Transactions on Automatic Control, Vol. AC-26, Feb. 1981, pp. 75-92.

[12] Systems Control, Inc., "F100 Multivariable Control Synthesis Program", AFAPL-TR-77-35, June 1977. 

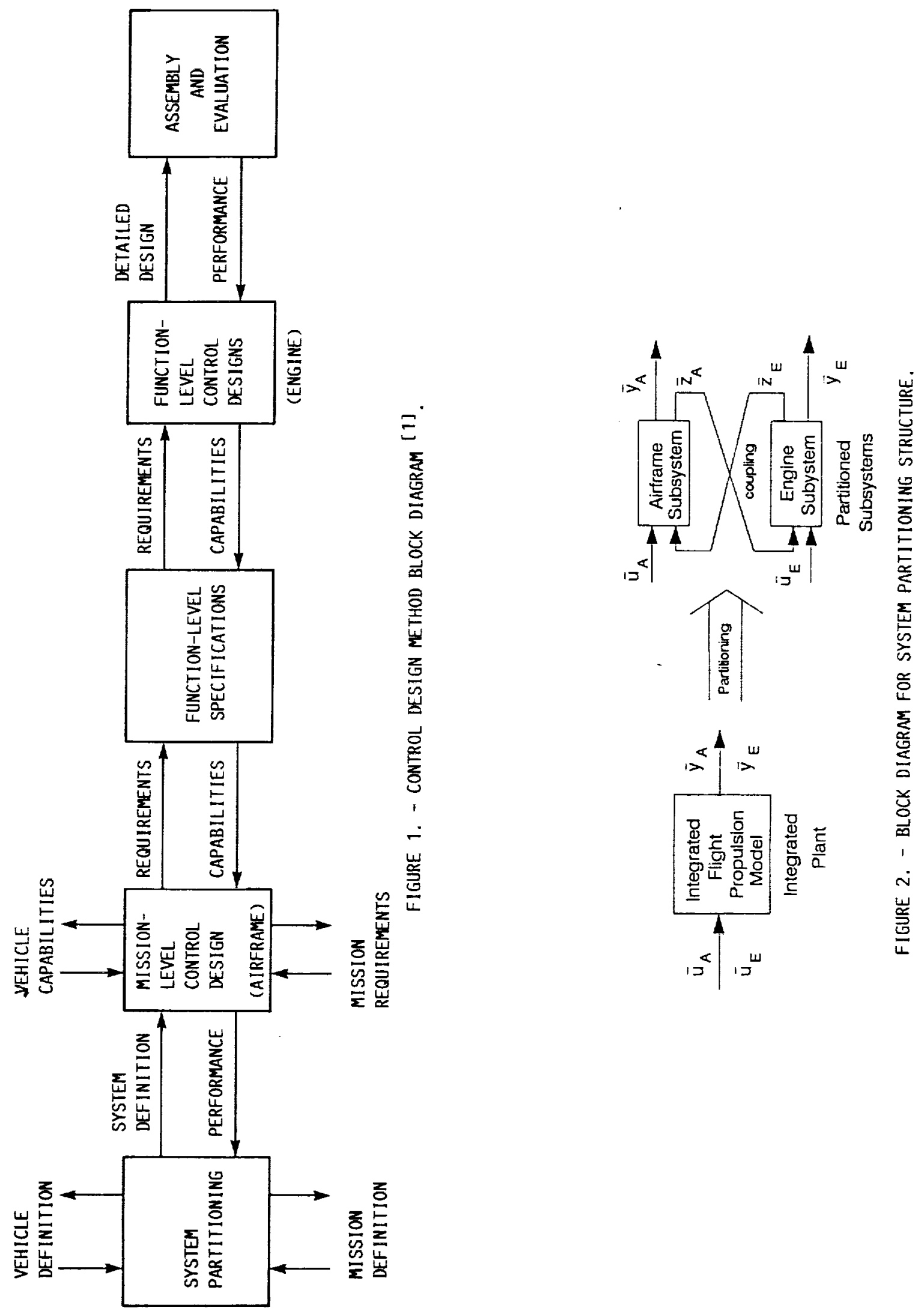


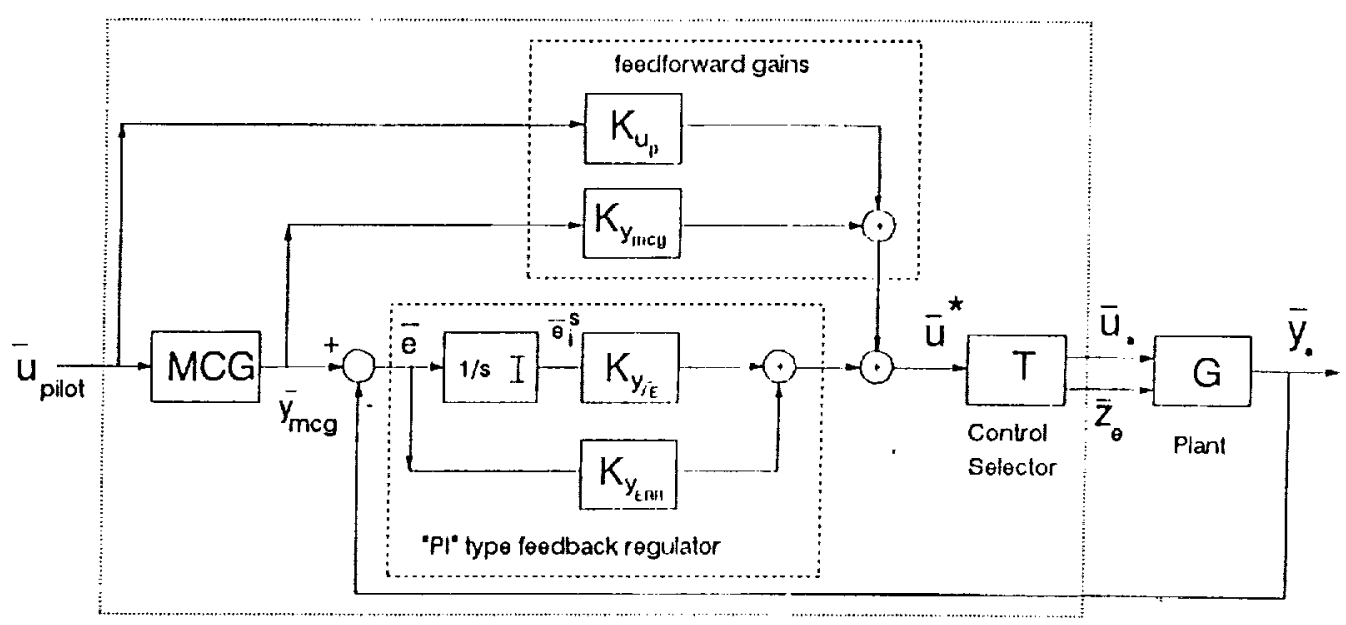

FIGURE 3. - HIGH LEVEL AIRFRAME CONTROL STRUCTURE.

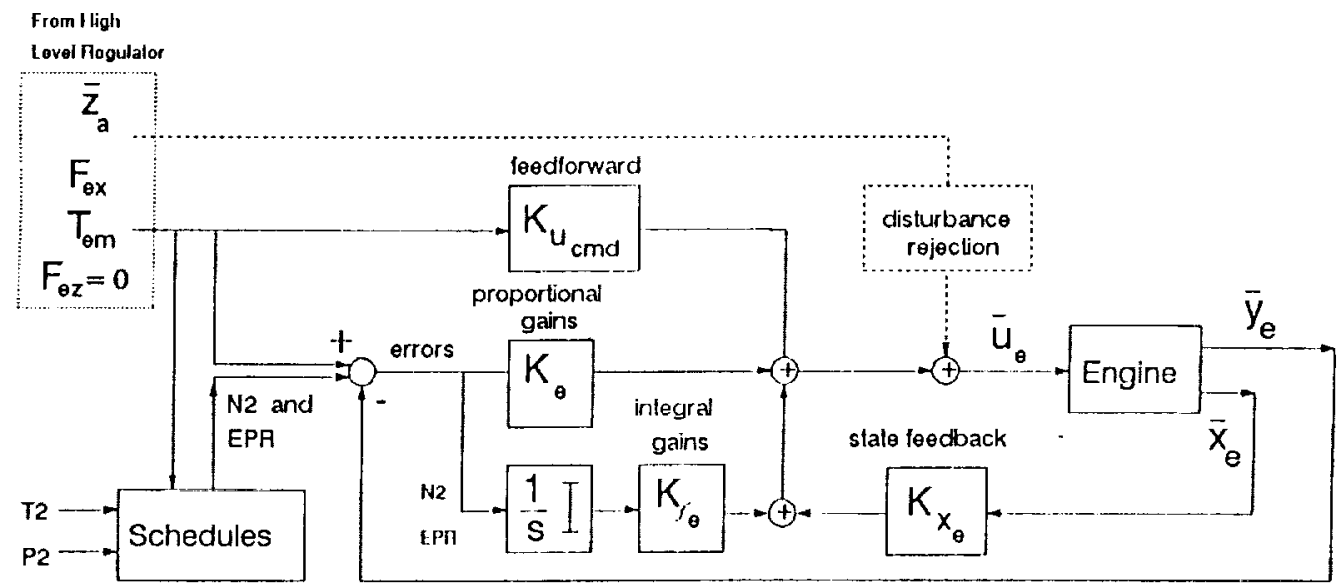

FIGURE 4. - LOW LEVEL ENGINE CONTROL STRUCTURE.

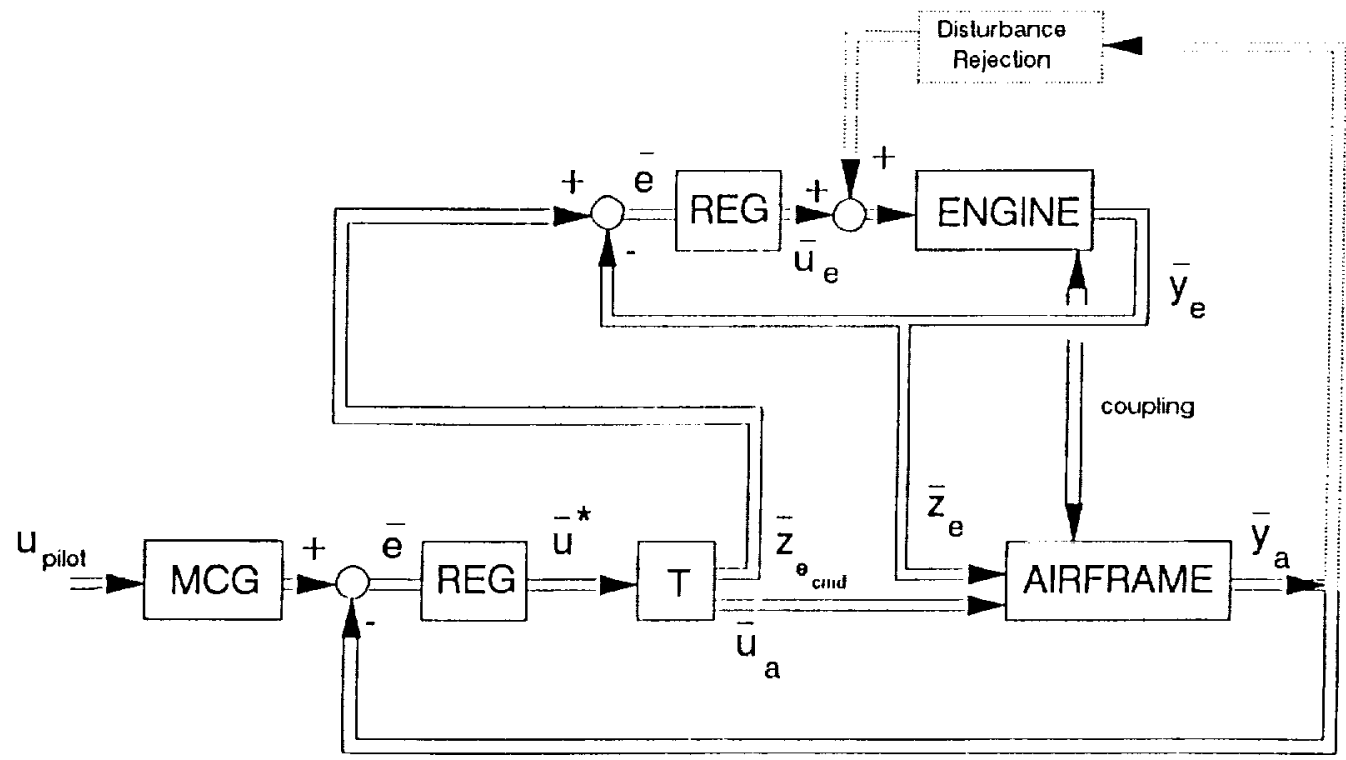

FIGURE 5. - DECENTRALIZED, HIERARCHICAL IFPC CONTROL STRUCTURE. 

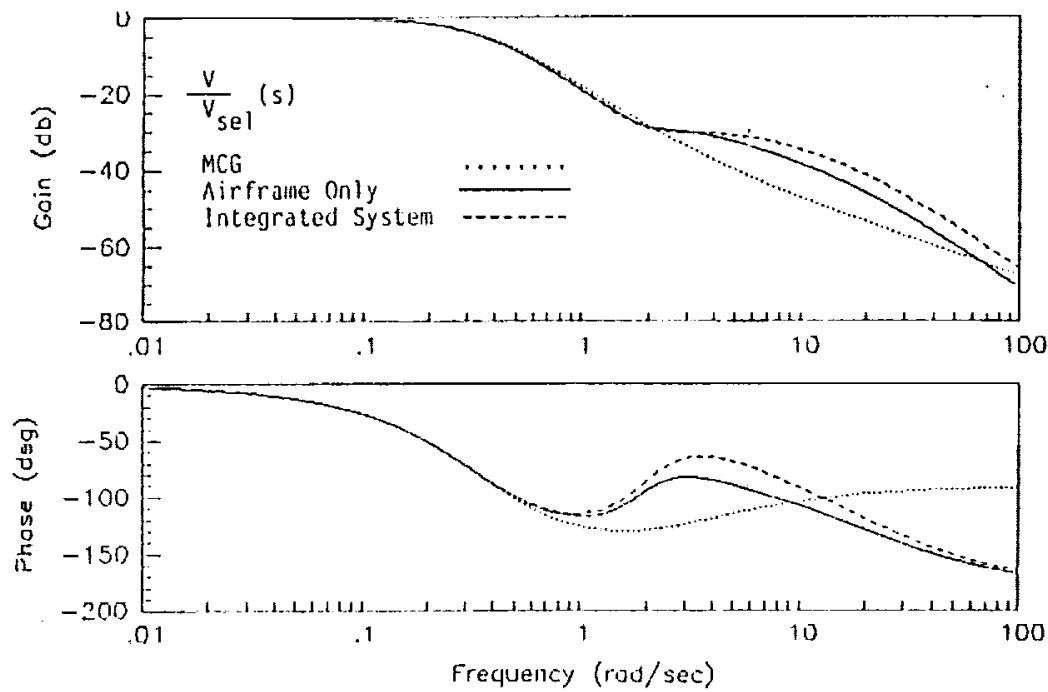

FIGURE 6. - V/V SEL $_{\text {TREQUENCY RESPONSE. }}$
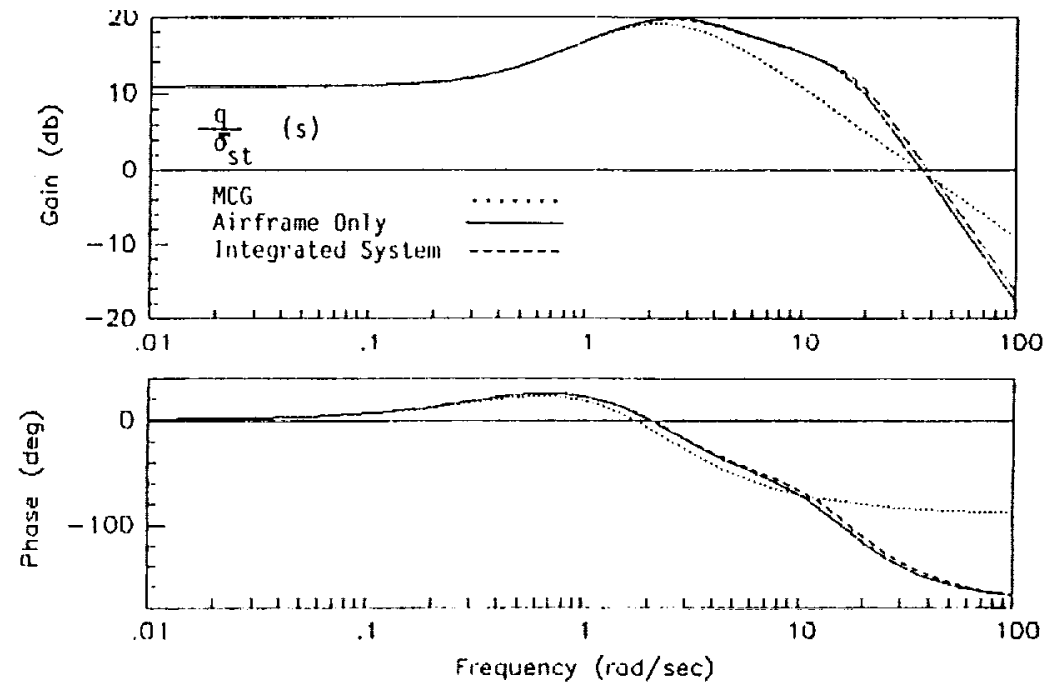

FIGURE $7 .-q / \delta_{S I}$ F ZEQUENCY RESPONSE. 

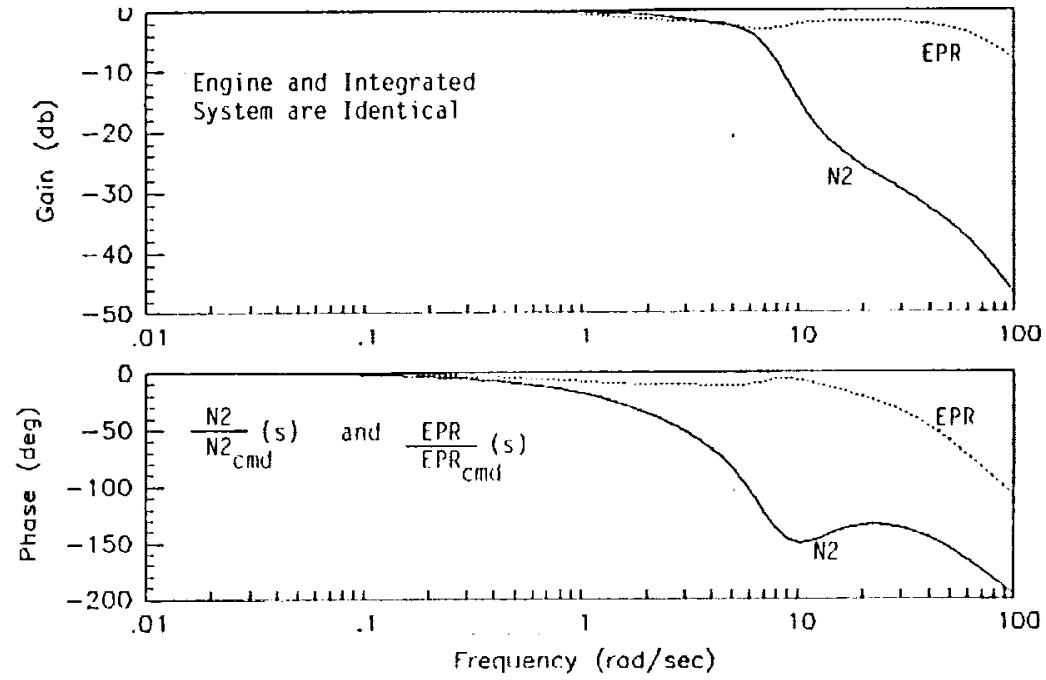

FIGURE 8. $-\frac{\mathrm{N} 2}{\mathrm{~N}^{2} \mathrm{cmd}}$ ANI) $\frac{\text { EPR }}{\mathrm{EPR}_{\mathrm{c} \text { IId }}}$ FREQUENCY RESPONSE.
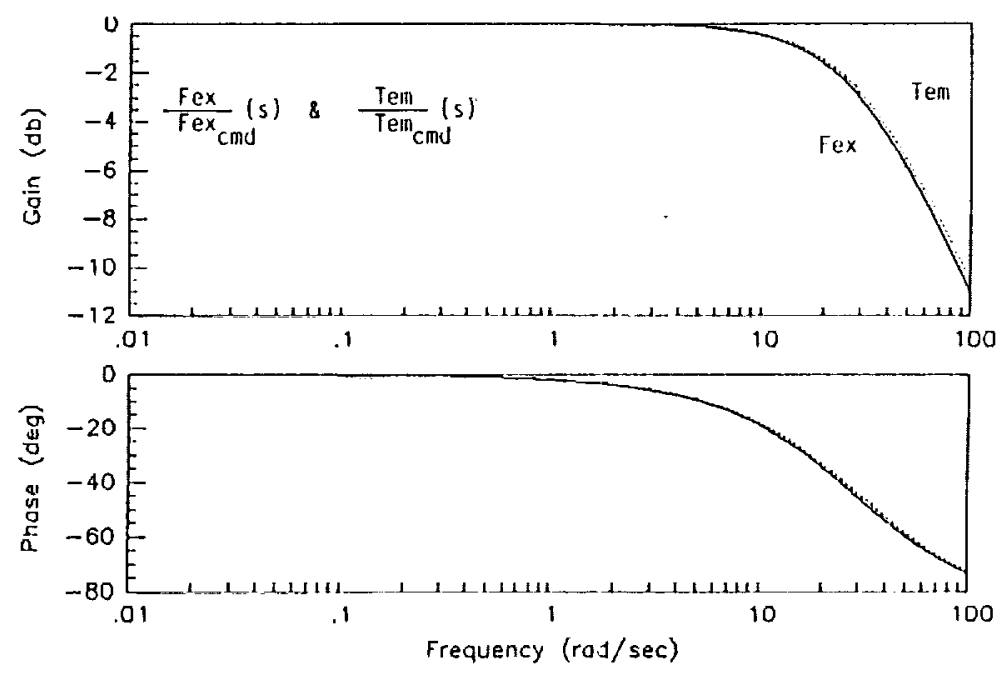

FIGURE 9. - $\frac{\text { Fex }}{\text { Fex }_{\mathrm{cm}}}$ AND $\frac{\text { Tem }}{\text { Tem }_{\mathrm{cmd}}}$ FREQUENCY RESPONSE. 


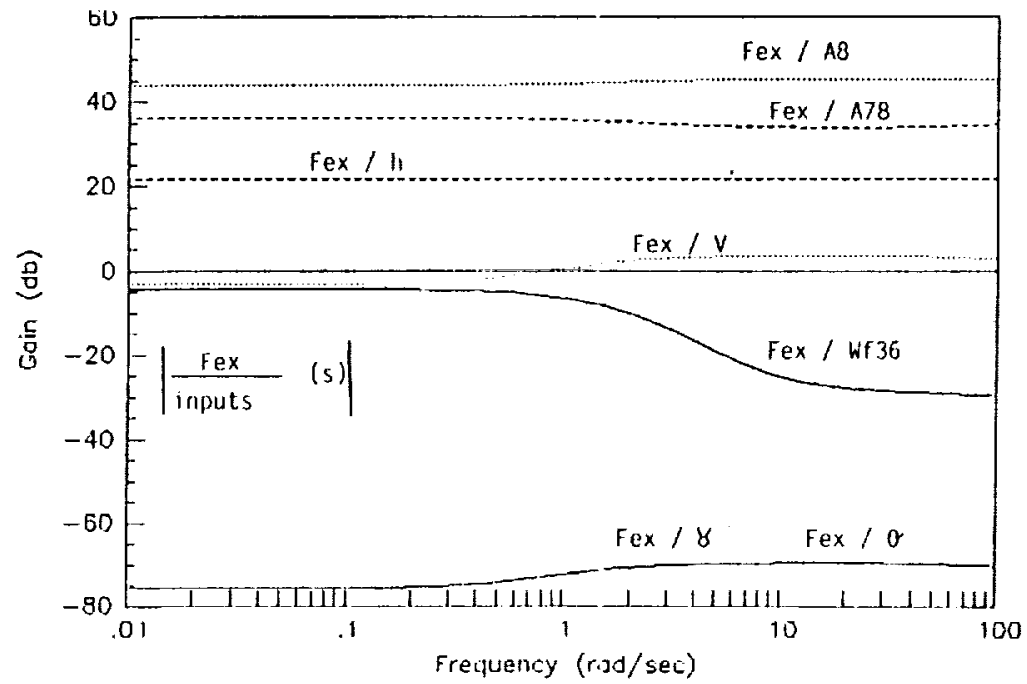

Frequency Response of Fex to Various Inputs

FIGURE 10. - AIRFRAME-TO-ENGINE COUPLING.
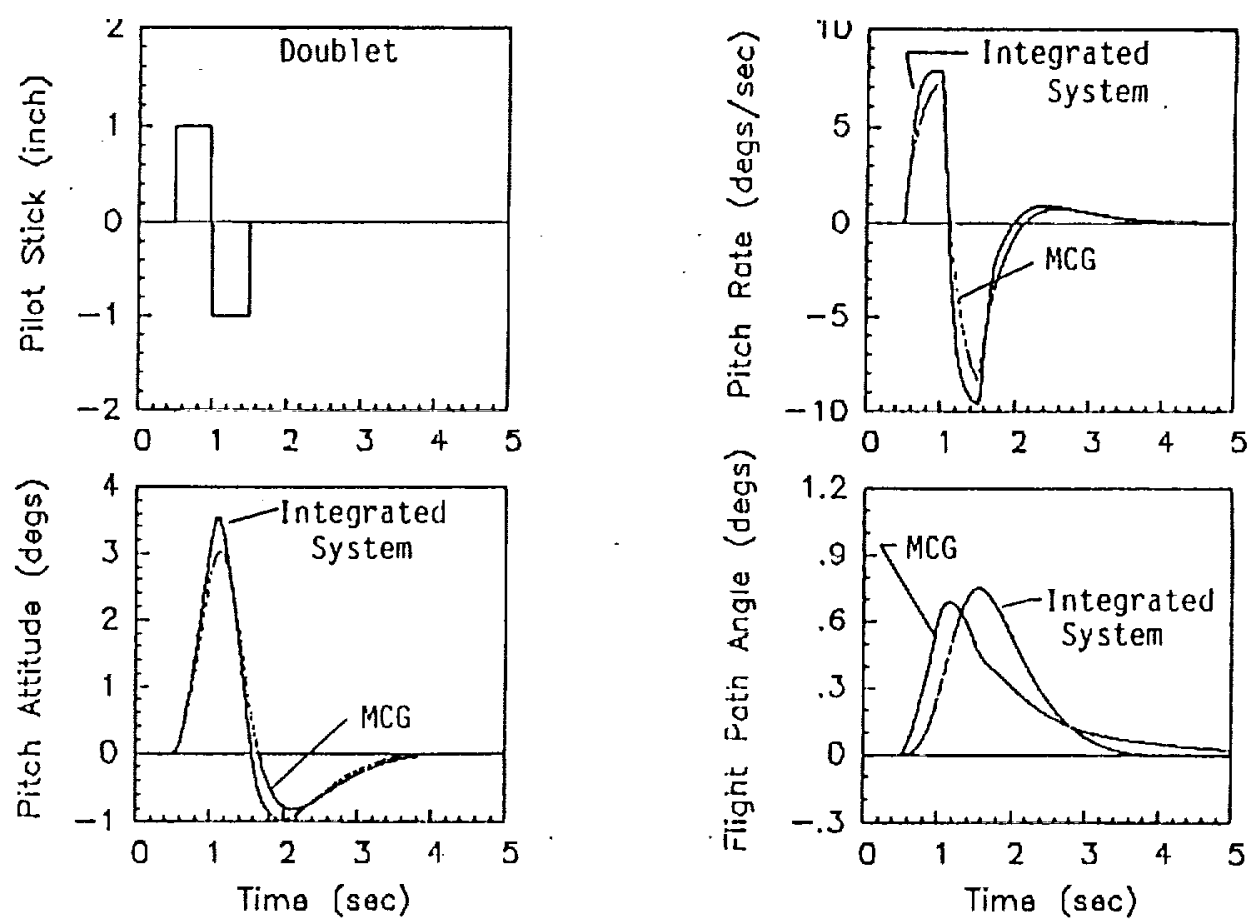

FIGURE 11. - AIRFRAME RESPONSE TO PILOT STICK DOUBLET. 

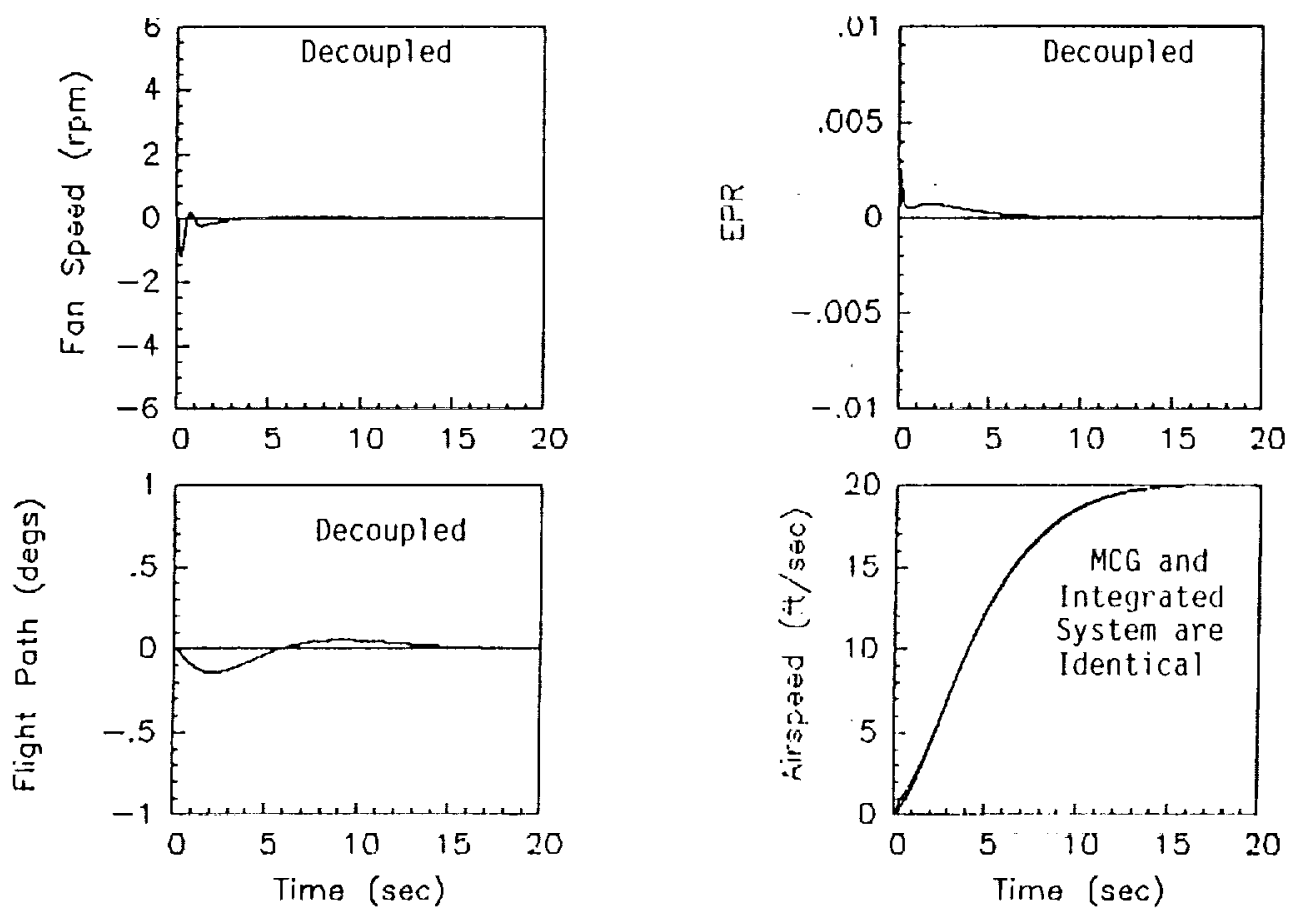

FIGURE 12. - INTEGRATED SYSTEM RESPONSE TO $V_{\text {SEL }}$ STEP $=20 \mathrm{FT} / \mathrm{s}$.

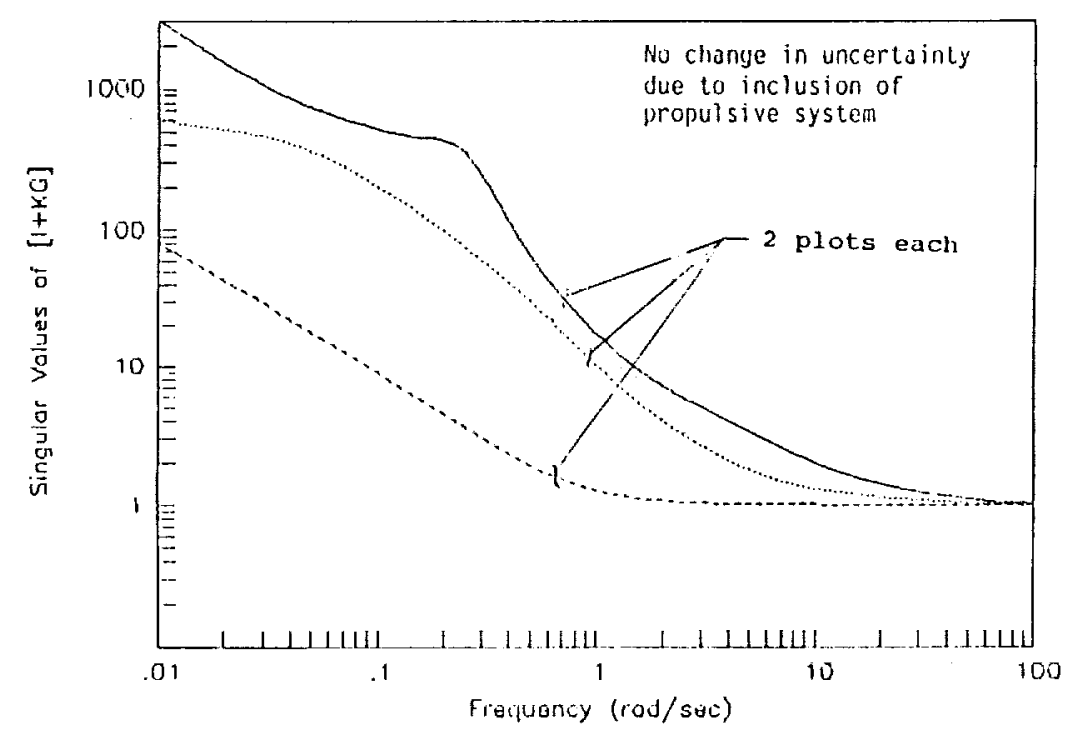

FIGURE 13. - CHANGE IN SINGULAR VALUES DUE TO THE ADDITION OF THE ENGINE SUBSYSTEM. 


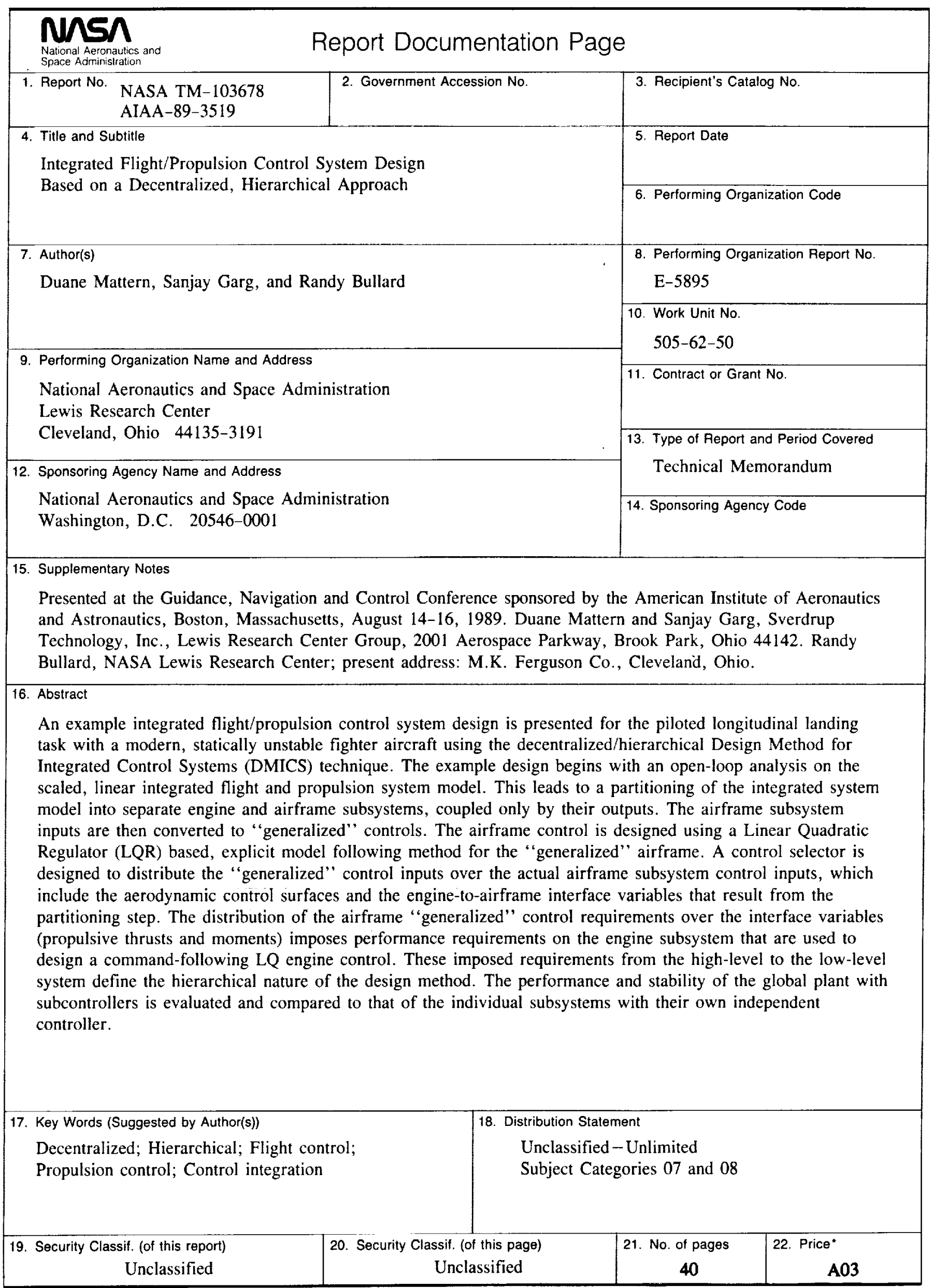

NASA FORM 1626 OCT $86 \quad$ "For sale by the National Technical Information Service, Springfield, Virginia 22161 